Article

\title{
Optimization of Novel Naproxen-Loaded Chitosan/ Carrageenan Nanocarrier-Based Gel for Topical Delivery: Ex Vivo, Histopathological, and In Vivo Evaluation
}

\author{
Sobia Noreen ${ }^{1}{ }^{(D}$, Fahad Pervaiz ${ }^{1, *}$, Akram Ashames ${ }^{2,3}{ }^{\mathbb{D}}$, Manal Buabeid ${ }^{3,4}$,*, Khairi Fahelelbom ${ }^{5}$, \\ Hina Shoukat ${ }^{1}$, Irsah Maqbool ${ }^{1}$ D and Ghulam Murtaza ${ }^{6, *}$
}

1 Department of Pharmaceutics, Faculty of Pharmacy, The Islamia University of Bahawalpur, Bahawalpur 63100, Pakistan; sobianoreen07@gmail.com (S.N.); hinashoukat50@yahoo.com (H.S.); irsamaqbool@yahoo.com (I.M.)

2 Department of Pharmaceutical Sciences, College of Pharmacy and Health Sciences, Ajman University, Ajman P.O. Box 346, United Arab Emirates; a.ashames@ajman.ac.ae

3 Medical and Bio-Allied Health Sciences Research Centre, Ajman University, Ajman P.O. Box 346, United Arab Emirates

4 Department of Clinical Sciences, College of Pharmacy and Health Sciences, Ajman University, Ajman P.O. Box 346, United Arab Emirates

5 Department of Pharmaceutical Sciences, College of Pharmacy, Al Ain University, Al Ain P.O. Box 64141, United Arab Emirates; khairi.mustafa@aau.ac.ae

check for updates

Citation: Noreen, S.; Pervaiz, F.;

Ashames, A.; Buabeid, M.;

Fahelelbom, K.; Shoukat, H.; Maqbool, I.; Murtaza, G.

Optimization of Novel Naproxen-

Loaded Chitosan/Carrageenan

Nanocarrier-Based Gel for Topical Delivery: Ex Vivo, Histopathological, and In Vivo Evaluation.

Pharmaceuticals 2021, 14, 557. https://

doi.org/10.3390/ph14060557

Academic Editors: María Ángeles Peña Fernández and Serge Mordon

Received: 11 May 2021

Accepted: 27 May 2021

Published: 11 June 2021

Publisher's Note: MDPI stays neutral with regard to jurisdictional claims in published maps and institutional affiliations.

Copyright: (c) 2021 by the authors. Licensee MDPI, Basel, Switzerland. This article is an open access article distributed under the terms and conditions of the Creative Commons Attribution (CC BY) license (https:/ / creativecommons.org/licenses/by/ $4.0 /)$.
6 Department of Pharmacy, COMSATS University Islamabad, Lahore Campus, Lahore 54000, Pakistan

* Correspondence: fahad.pervaiz@iub.edu.pk (F.P.); m.buabeid@ajman.ac.ae (M.B.); gmdogar356@gmail.com (G.M.)

\begin{abstract}
Naproxen (NAP) is commonly used for pain, inflammation, and stiffness associated with arthritis. However, systemic administration is linked with several gastrointestinal tract (GIT) side effects. The present work aims to prepare and evaluate NAP nanoparticulate shells of chitosan (CS) and carrageenan (CRG) loaded into a Carbopol 940 (Ca-940) gel system with unique features of sustained drug delivery as well as improved permeation through a topical route. Moreover, this study aims to evaluate its ex vivo, histopathological, and in vivo anti-inflammatory activity in albino Wistar rats. The percentage of ex vivo drug permeation patterns in the optimized formulation (No) was higher $(88.66 \%)$ than the control gel $(36.195 \%)$. Oral toxicity studies of developed nanoparticles in albino rabbits showed that the NAP-loaded CS/CRG are non-toxic and, upon histopathological evaluation, no sign of incompatibility was observed compared to the control group. A In Vivo study showed that the optimized gel formulation (No) was more effective than the control gel (Nc) in treating arthritis-associated inflammation. The sustained permeation and the absence of skin irritation make this novel NAP nanoparticle-loaded gel based on CS/CRG a suitable drug delivery system for topical application and has the potential for improved patient compliance and reduced GIT-related side effects in arthritis.
\end{abstract}

Keywords: chitosan; carrageenan; anti-inflammatory; naproxen; polyelectrolyte complexation; nanocarriers; Ca-940 gel; toxicity study

\section{Introduction}

Rheumatoid arthritis (RA) is an inflammatory disease associated with severe pain, stiffness, and peripheral joint swelling. Inflammatory events are initiated from the interaction of antigen-presenting cells (APCs) with CD+T cells. Complex cell-cell interaction leads to macrophage activation with an enormous release of proinflammatory cytokines such as IL-1 and TNF $\alpha$. These cytokines activate synovial fibroblasts and chondrocytes in surrounding articular cartilage and release enzymes that destroy proteoglycans and collagen, causing tissue destruction [1]. RA mainly occurs in women as compared to men. 
Around $1-2 \%$ of the general population is affected worldwide by arthritis [2]. Non-steroidal anti-inflammatory drugs (NSAIDs) are commonly prescribed to treat inflammatory, acute, and chronic pain conditions [3].

Naproxen (NAP), (2S)-2-(6-methoxynaphthalen-2-yl) propanoate, belongs to NSAIDs' propionic acid class. It is generally used to treat pain, pyrexia, inflammation, and stiffness produced by osteoarthritis, rheumatoid arthritis, injuries, tendinitis, bursitis, and psoriatic arthritis [4]. Therefore, the designing of naproxen's formulation with an improved controlled release pattern will possibly have exceptional advantages in treating the body's inflammatory and painful states [5].

Anti-inflammatory effects of NAP are mediated by the inhibition of COX-1 and COX-2, which are responsible for prostaglandin E2 production when activated by inflammatory mediators such as tumor necrosis factor and interleukins [6]. The use of oral NSAIDs can damage the gastrointestinal tract, leading to peptic ulcers and hemorrhagic disorders [7]. Analogous to other NSAIDs, naproxen also causes gastric bleeding and ulceration after oral administration. The mechanisms underlying these gastric damage events include prostaglandin-mediated, increased gastric acid secretion, reduced mucus, bicarbonate secretion, and decreased mucosal cell proliferation and blood flow [8].

From the perspective of the side effects related to naproxen's oral route, it can be administered safely via topical drug delivery with minimal side effects, including peptic ulcer disease and GI hemorrhage. Additionally, the topical approach offers certain distinct advantages: a practically larger surface area of skin for absorption, local drug delivery to affected tissues, a non-invasive route, eliminated side effects, maintenance of plasmadrug concentration, ease of removal or replacement, and the avoidance of presystemic metabolism [9]. Typically, a polyelectrolyte complex (PEC) is the formation of the complex in a reaction of a polyanion $(\mathrm{PA}-$ ) with counter cations $(\mathrm{CC}+)$, and a polycation $(\mathrm{PC}+)$ with counter anions $(\mathrm{CA}-)$ [10]. CS is a naturally occurring polysaccharide with [(1-4) 2-amino 2-deoxy- $\beta$-D-glucan] linkage [11]. Owing to its outstanding characteristics, including nontoxicity, biodegradability, biocompatibility [12], and gel- and film-forming properties [13], it has been broadly employed in the fabrication of novel polymeric drug delivery systems [14]. Its anti-inflammatory, antioxidant, and anti-microbial characteristics rank CS as an ideal vehicle for transdermal drug delivery [15]. Various studies reported the behavior of CS for TDD applications [16-19]. Bhaskar et al. prepared solid lipid nanoparticles (SLNs) and nanostructured lipid carriers (NLCs) for enhanced transdermal delivery of flurbiprofen by using chitosan as a carrier [20]. CRG is a linear anionic polysaccharide that contains many sulfate groups in the galactose dimers [21].

In the biomedical and pharmaceutical sciences, the blending of nanoparticles (NPs) with CRG magnifies their properties, and the sustained release characteristics are improved due to carrageenan's gelling properties [22]. Negatively charged carrageenan reacts with positively charged chitosan in the crosslinker's presence to form CS/CRG sustained release nanoparticles. The positive surface charge and size of CS/CRG nanoparticles are suitable for penetrating epithelial surfaces [23]. Therefore, CRG has been used in several studies to develop a transdermal delivery system [24].

The current study aimed to develop a novel naproxen-loaded CS/CRG polymeric nanoparticulate-based gel system using a polyelectrolyte complexation technique. Naproxenloaded chitosan/carrageenan nanoparticles were incorporated into Ca-940 gel and evaluated for transdermal delivery of naproxen by ex vivo permeation and in vivo antiinflammatory studies. The histopathological slides also performed an acute oral toxicity study. To the best of our knowledge, no study has incorporated NAP-loaded CS/CRG nanoparticles in the gel for TDD application in inflammatory conditions such as arthritis to minimize systemic side effects of NAP. 


\section{Results and Discussion}

\subsection{Preparation and Optimization of Naproxen-Loaded Nanoparticles}

NAP-loaded CS/CRG NPs were successfully prepared by the polyelectrolyte complexation method. Once the polymer-containing solutions were mixed, PEC formation occurred among the amino groups of CS, having a positive charge. The sulfate and phosphate groups of CRG and TPP, respectively, having a negative charge, accelerated nanoparticle formation. STPP promotes a strong interaction, as it offers a cross-linking effect. At a higher percentage $(>0.1 \%)$ of CRG, precipitation was observed, and a further increase in CRG (1\%) led to clump formation. However, when the lower percentage of CRG was employed, no nanoparticle formation occurred. The high concentration of CRG resulted in less engagement of amino groups in neutralization with the sulfate group, causing precipitation. On the contrary, a lower concentration of carrageenan did not support nanoparticle development due to the insufficient volume of counter ions. After washing away the unreacted components and freeze-drying the concentrated nanoparticle suspension, dried nanoparticles were obtained [25].

\subsection{Nanoparticles Characterization}

\subsubsection{Scanning Electron Microscopic Analysis}

SEM analysis for the NAP-loaded CS/CRG nanoparticle formulations (lyophilized and in water dispersion) was performed. Figure 1a,c demonstrates the SEM microphotographs of N11 (in water dispersion) and the optimized formulation (No) (in water dispersion), respectively. While Figure 1b,d depicts the SEM images of N11 (lyophilized) and the optimized formulation (No) (lyophilized), which confirmed a compact and solid structure, presenting the tendency to display a spherical shape [26].

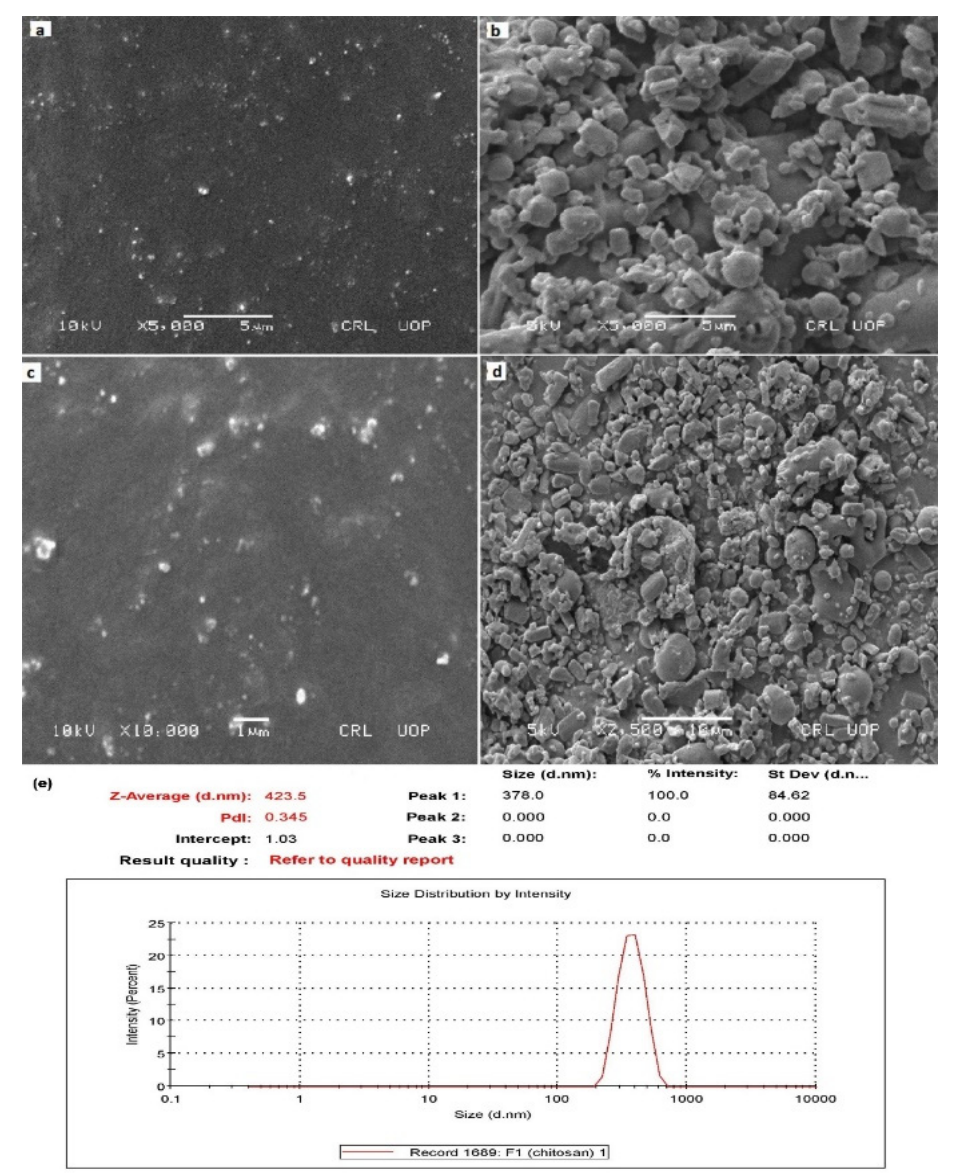

Figure 1. (a,c) SEM microphotographs of N11 and optimized No naproxen-loaded CS/CRG nanoparticle formulation liquid dispersion; (b,d) lyophilized; (e) and particle size and PDI of N15 formulation. 


\subsubsection{FTIR Spectra of Naproxen-Loaded Nanoparticles Formulation}

FTIR spectra of NAP showed absorption bands at 1028, 854,1630, and $1727 \mathrm{~cm}^{-1}$. The vibration modes were identified at 1028.96 and $854.78 \mathrm{~cm}^{-1}$ parallel to $\mathrm{C}-\mathrm{O}-\mathrm{C}$ bonds in NAP. Moreover, the band at $1733.52 \mathrm{~cm}^{-1}$ was parallel to the carbonyl stretching region. NAP absorption bands at $1028,854,1630$, and $1727 \mathrm{~cm}^{-1}$ in the carbonyl stretching region remained unchanged, specifying that there was no drug-polymer hydrogen bonding interaction [27-29]. The FTIR analysis of CS revealed an amide I peak at a range of 1700$1500 \mathrm{~cm}^{-1}$ (1652.66) and an amide II peak at $1586.71 \mathrm{~cm}^{-1}$. The broadband at $3366.08 \mathrm{~cm}^{-1}$ corresponded to the stretching vibration of hydroxyl groups at a range of $3400-3300 \mathrm{~cm}^{-1}$. The broad peak at $1162.57 \mathrm{~cm}^{-1}$ represented asymmetric stretching of $\mathrm{C}-\mathrm{O}-\mathrm{C}$ in a glycosidic linkage, and the peak at $1029.32 \mathrm{~cm}^{-1}$ presented the stretching vibration of $\mathrm{C}-\mathrm{O}$ [30]. FTIR spectra of carrageenan at $925.16 \mathrm{~cm}^{-1}$ were attributed to the $\mathrm{C}-\mathrm{O}-\mathrm{C}$ vibration of the 3 , 6 -anhydro-d-galactose residue. The intense band at $1647.04 \mathrm{~cm}^{-1}$ linked with the structural water deformation band [31].

A new absorption band confirmed the development of the CS/CRG polyelectrolyte complex at $1505 \mathrm{~cm}^{-1}$ due to the appearance of the $-\mathrm{NH} 3$ group. Moreover, both amide peaks of CS transformed into a singlet band at $1630.90 \mathrm{~cm}^{-1}$, and NH2 groups were also recognized (Figure 2). Characteristic peaks of CRG were recognized in the NPS spectrum, such as sulfate groups at $1263.93 \mathrm{~cm}^{-1}, 3,6$-anhydrogalactose at $925.31 \mathrm{~cm}^{-1}$, and galactose-4-sulfate at $854.56 \mathrm{~cm}^{-1}$. This indicated the interaction between protonated amine groups of CS and sulfate groups of carrageenan in the successful formation of the CS/CRG polyelectrolyte complex. No prominent change was observed in the peaks of drug, polymer, and physical mixtures, specifying the absence of any hydrogen bonding interaction between drug and polymer. The NAP-loaded CS/CRG nanoparticle optimized formulation spectra showed no interaction between protonated amine groups of CS and sulfates groups of carrageenan in the successful formation of the CS/CRG polyelectrolyte complex $[27,32]$.

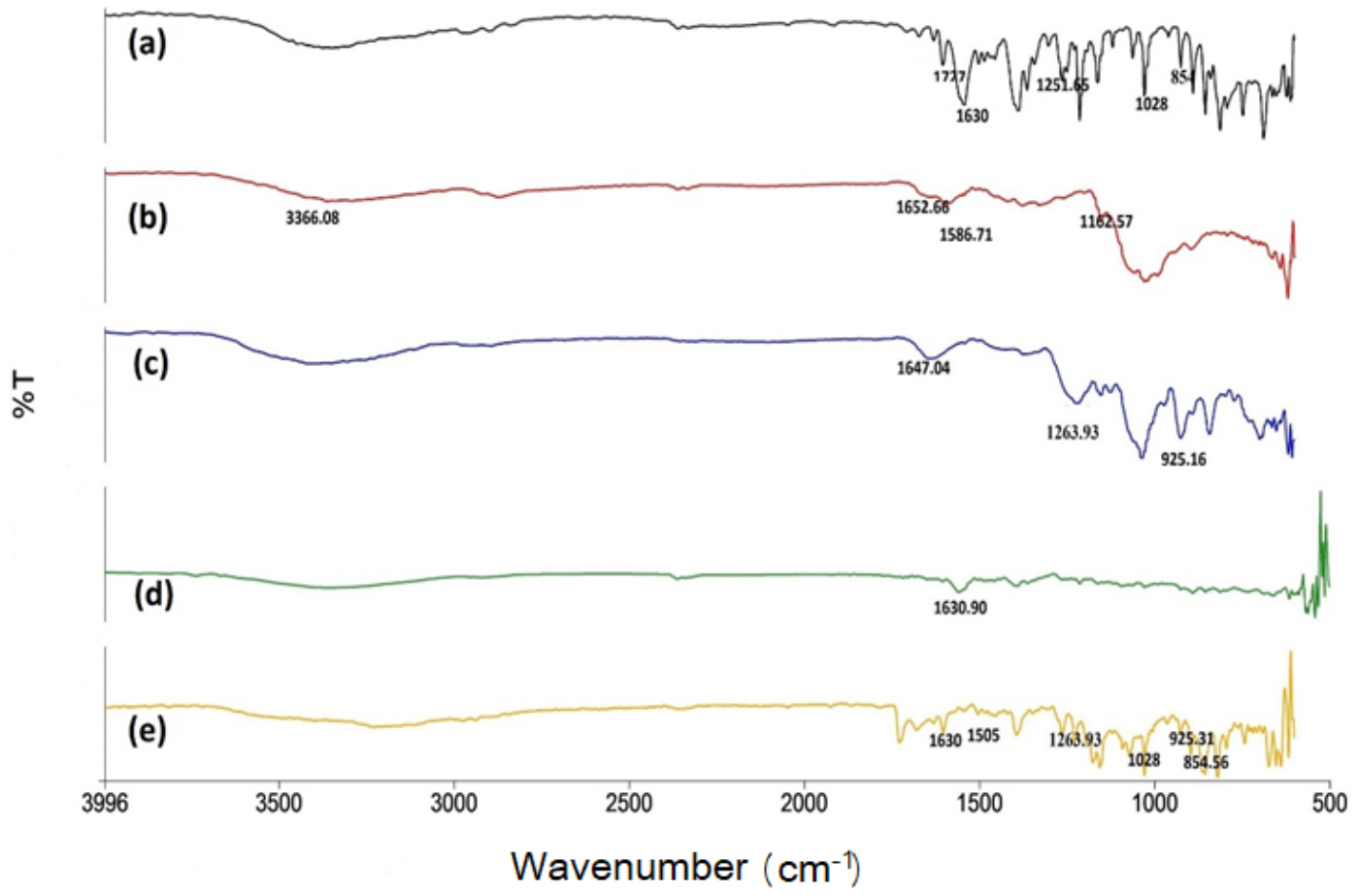

Figure 2. (a) FTIR spectra of naproxen, (b) chitosan, (c) carrageenan, (d) physical mixture, and (e) optimized formulation.

\subsubsection{Powdered X-ray Diffraction (pXRD)}

In Figure 3, the pXRD diffraction patterns of NAP, CS, CRG, and drug-loaded CS/CRGs nanoparticles are displayed. The diffraction pattern of pure NAP showed the crystalline 
nature of the drug and distinct diffraction peaks at $2 \theta$ value of $15.2^{\circ}, 17.0^{\circ}, 18.08^{\circ}, 20.70^{\circ}$, $24.40^{\circ}$, and $28.3^{\circ}$, which are characteristic peaks for NAP [33]. The diffraction pattern of CS shows its semi-crystalline nature and revealed a reflection fall at $10^{\circ}$ and $20^{\circ}$ [34]. The XRD diffraction pattern of pure carrageenan exhibits sharp peaks at $2 \theta=20^{\circ}, 23.05^{\circ}, 22.35^{\circ}$, $28.79^{\circ}, 31.70^{\circ}, 32.82^{\circ}, 39.81^{\circ}$, and $45.66^{\circ}$. These peaks represent the amorphous nature of the polymer [35]. Crystallinity peaks of pure drug and polymers are observed in the XRD analysis of physical mixture (PM) representing no interaction among the formulation components. In the drug-loaded polyelectrolyte complex nanoparticles, a diffuse pattern with no precise, sharp peaks is observed. The PEC presents a reduction in NAP peak intensity, showing the existence of an amorphous form when loaded with CS/CRG nanoparticles.

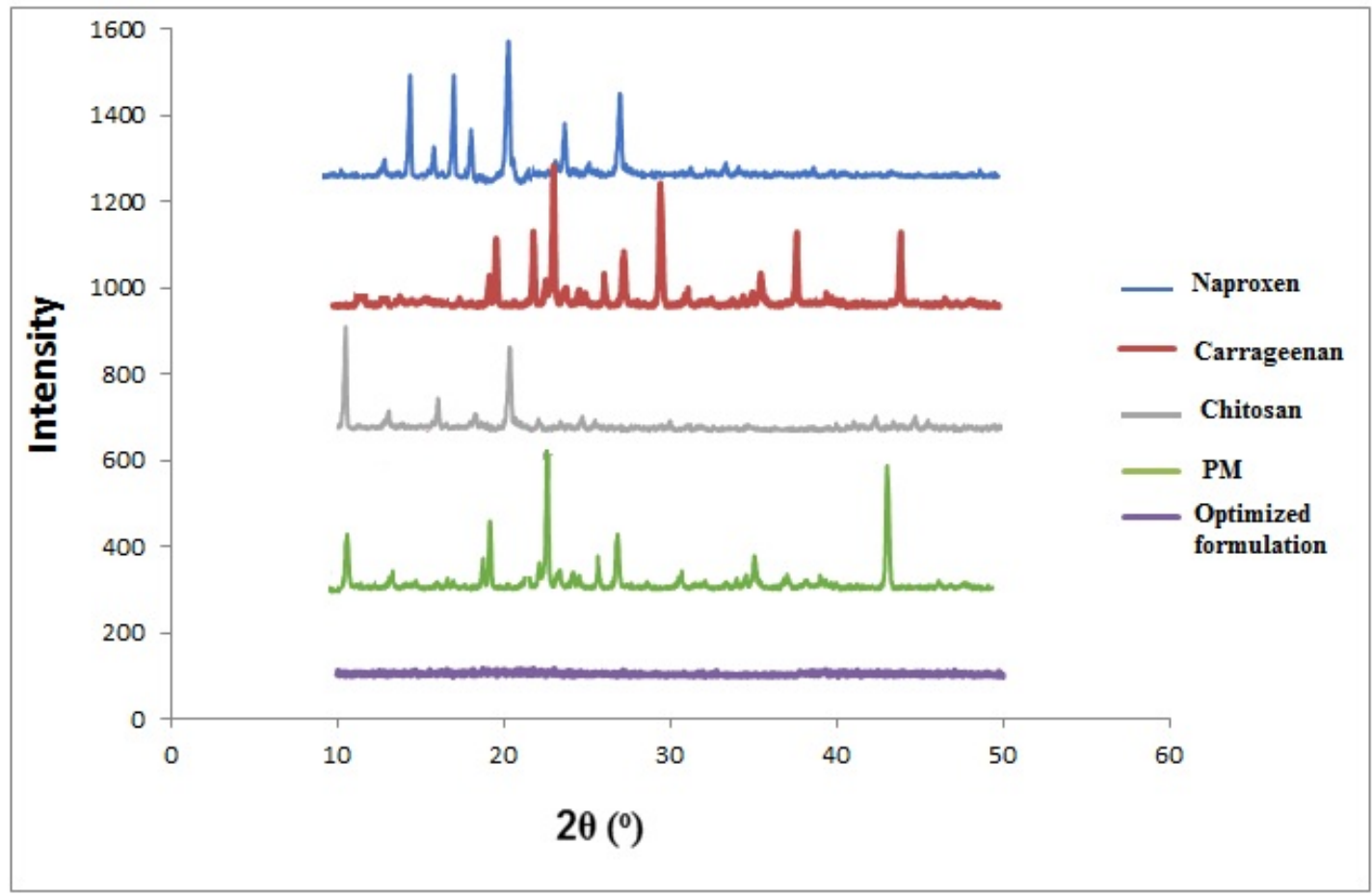

Figure 3. XRD spectra of naproxen, carrageenan, chitosan, physical mixture, and optimized formulation.

\subsubsection{Entrapment Efficiency}

Formulation N11 showed the lowest EE (93.33\%), while N1 exhibited maximum entrapment efficiency of $97.55 \%$ (Table 1). It was revealed by ANOVA (Table 2) that the EE exhibited significant differences when changing CRG concentration (X1) and drug concentration $(\mathrm{X} 2)$, while a non-significant effect was observed when altering stirring speed (X3).

The quadratic expression relating the EE with independent variables is presented in Equation (1):

Entrapment Efficiency $(\mathrm{Y} 1)=+95.20+1.69 \times \mathrm{A}-0.58 \times \mathrm{B}-0.12 \times \mathrm{C}+0.025 \times \mathrm{A} \times \mathrm{B}-0.065 \times \mathrm{A} \times \mathrm{C}-$ $0.097 \times \mathrm{B} \times \mathrm{C}+0.26 \times \mathrm{A} 2+9.750 \mathrm{E}-003 \times \mathrm{B} 2-0.090 \times \mathrm{C} 2$

A significant $(p<0.05)$ increase in the EE was noticed with the increased concentration of CRG (Table 2 and Figure 4) in the preparation of drug-loaded CS/CRG nanoparticles. This is due to the increase in CRG concentration increased the internal phase's viscosity and thickness, leading to ionic cross-linking of CRG with free CS in the dispersion. The formulations showed a significant $(p<0.05)$ increase in drug entrapment by decreasing the formulations' drug amounts. This is because a high amount of drug increases the solvent's viscosity, resulting in larger-sized particles and increasing the hardening time of the particles, which provided sufficient time for the drug to move out of particles. Figure 4 
reveals a non-significant decrease $(p>0.05)$ in the EE by increasing stirring speed from 600 to $900 \mathrm{rpm}$. This is because smaller particles have a large surface area, and there was further diffusion of the drug into the continuous phase [36-38].

Table 1. Effect of formulation components and process variables on different characteristics.

\begin{tabular}{|c|c|c|c|c|c|c|}
\hline $\begin{array}{l}\text { Formulation } \\
\text { Code }\end{array}$ & $\begin{array}{c}\text { Entrapment } \\
\text { Efficiency (\%) }\end{array}$ & $\begin{array}{l}\text { Particle Size } \\
\text { (nm) }\end{array}$ & PDI & $\begin{array}{l}\text { Zeta Potential } \\
(\mathrm{mV})\end{array}$ & $\begin{array}{c}\% \text { Cumulative } \\
\text { Drug Permeation }\end{array}$ & $\%$ Yield \\
\hline N1 & $97.55 \%$ & $342.45 \pm 16.33$ & 0.308 & $+25 \pm 0.9$ & 86.98 & $71.76 \%$ \\
\hline N2 & $95.12 \%$ & $264.33 \pm 35.78$ & 0.422 & $+29 \pm 1.3$ & 89.66 & $70.46 \%$ \\
\hline N3 & $97.08 \%$ & $332.29 \pm 8.43$ & 0.318 & $+26 \pm 1.9$ & 90.34 & $72.48 \%$ \\
\hline N4 & $94.12 \%$ & $162.75 \pm 22.43$ & 0.510 & $+34 \pm 1.1$ & 93.33 & $67.01 \%$ \\
\hline N5 & $95.25 \%$ & $264.33 \pm 35.78$ & 0.422 & $+34 \pm 1.6$ & 89.66 & $70.54 \%$ \\
\hline N6 & $94.66 \%$ & $277.54 \pm 6.74$ & 0.443 & $+33 \pm 3.1$ & 90.25 & $71.61 \%$ \\
\hline N7 & $96.94 \%$ & $362.43 \pm 54.64$ & 0.355 & $+27 \pm 2.6$ & 85.66 & $72.72 \%$ \\
\hline N8 & $95.36 \%$ & $264.33 \pm 35.78$ & 0.422 & $+33 \pm 3.1$ & 89.66 & $70.22 \%$ \\
\hline N9 & $95.08 \%$ & $264.33 \pm 35.78$ & 0.422 & $+34 \pm 1.1$ & 89.66 & $70.72 \%$ \\
\hline N10 & $93.66 \%$ & $156.78 \pm 45.53$ & 0.504 & $+35 \pm 2.1$ & 93.66 & $67.26 \%$ \\
\hline N11 & $93.33 \%$ & $176.68 \pm 27.03$ & 0.512 & $+33 \pm 0.8$ & 92.34 & $67.96 \%$ \\
\hline N12 & $95.77 \%$ & $255.38 \pm 18.43$ & 0.465 & $+30 \pm 1.3$ & 88.93 & $69.92 \%$ \\
\hline N13 & $96.03 \%$ & $243.22 \pm 10.55$ & 0.412 & $+29 \pm 0.6$ & 91.45 & $69.72 \%$ \\
\hline N14 & $95.18 \%$ & $264.33 \pm 35.78$ & 0.422 & $+33 \pm 3.1$ & 89.66 & $70.60 \%$ \\
\hline N15 & $96.86 \%$ & $378.0 \pm 84.62$ & 0.345 & $+28 \pm 2.3$ & 85.47 & $73.96 \%$ \\
\hline N16 & $94.01 \%$ & $290.08 \pm 24.22$ & 0.454 & $+31 \pm 0.4$ & 88.23 & $69.53 \%$ \\
\hline N17 & $93.78 \%$ & $188.32 \pm 16.69$ & 0.521 & $+33 \pm 0.8$ & 90.76 & $67.46 \%$ \\
\hline N18 & $90.22 \%$ & $407.20 \pm 84.62$ & 0.533 & $+26 \pm 2.1$ & 76.80 & $53.2 \%$ \\
\hline N19 & $89.34 \%$ & $674.20 \pm 47.48$ & 0.736 & $+12 \pm 2.2$ & 63.34 & $28 \%$ \\
\hline No (optimized) & $95.26 \%$ & $355.7 \pm 79.8$ & 0.381 & $+25 \pm 3.1$ & 88.66 & $70.78 \%$ \\
\hline
\end{tabular}

Table 2. ANOVA test values of dependent response variables.

\begin{tabular}{|c|c|c|c|}
\hline Sr. No. & Response Variables & Statistical Term & $p$-Value \\
\hline \multirow{3}{*}{1.} & \multirow{3}{*}{ Entrapment efficiency } & Polymer concentration & 0.0001 \\
\hline & & Drug concentration & 0.0001 \\
\hline & & Stirring speed & 0.2258 \\
\hline \multirow{3}{*}{2.} & \multirow{3}{*}{ Particle size } & Polymer concentration & 0.0001 \\
\hline & & Drug concentration & 0.0005 \\
\hline & & Stirring speed & 0.0033 \\
\hline \multirow{3}{*}{3.} & \multirow{3}{*}{$\begin{array}{l}\% \text { cumulative drug } \\
\text { permeation }\end{array}$} & Polymer concentration & 0.0001 \\
\hline & & Drug concentration & 0.0810 \\
\hline & & Stirring speed & 0. 0008 \\
\hline
\end{tabular}




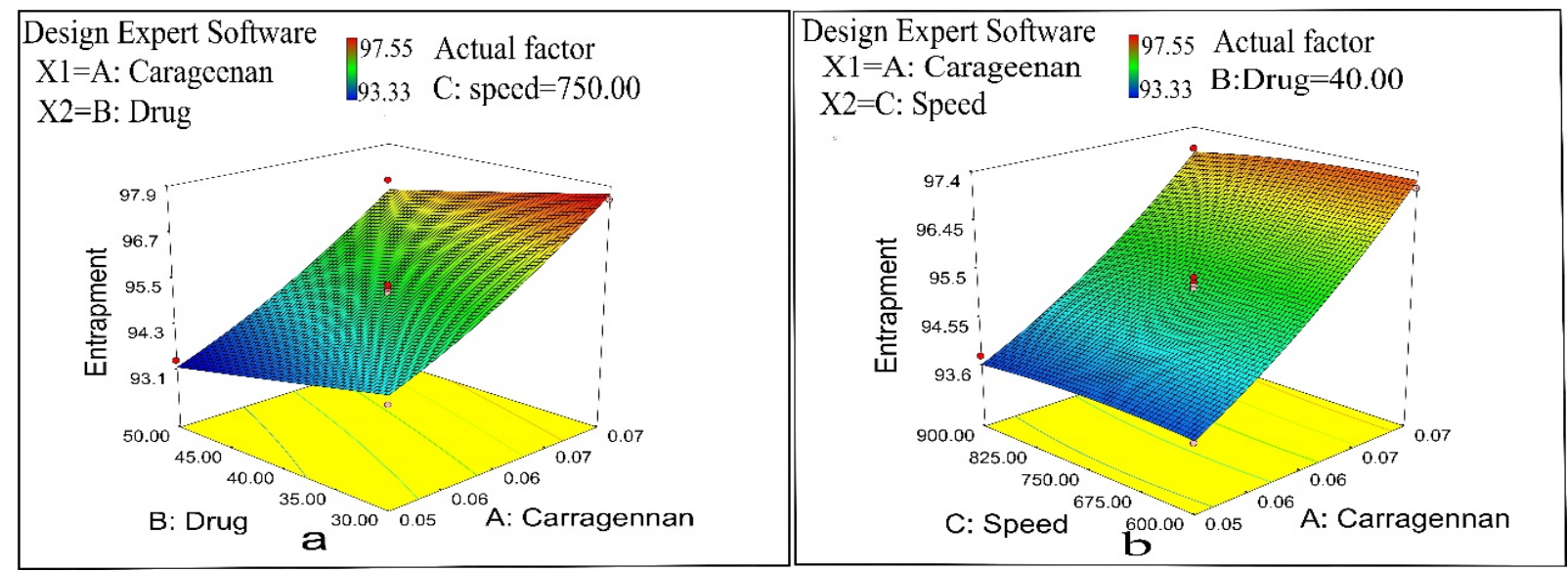

Figure 4. (a) Influence of polymer concentration and drug concentration on entrapment efficiency and (b) influence of polymer concentration and stirring speed on entrapment efficiency.

2.2.5. Zetasizer, Polydispersity Index, and Zeta Potential Determination of NAP-Loaded Nanoparticles

NAP-loaded CS/CRG nanoparticle size depends on three variables: carrageenan concentration, drug concentration, and complexation time. Formulation N15 displayed maximum particle size $(378.0 \pm 84.62 \mathrm{~nm})$ (Figure 1$)$, whereas minimum particle size was observed in formulation N10 (156.78 $\pm 45.53 \mathrm{~nm})$ (Table 1$)$. The polydispersity (PDI) value of the CS/CRG nanoparticles ranged between 0.308-0.521, thus representing a narrow and promising particle size distribution (PDI < 0.5) (Table 1). The PDI usually increased according to the increase in the CS to CRG mass ratio $[39,40]$. CS/CRG nanoparticles showed positive zeta potential, having a range between +25 and $+35 \mathrm{mV}$ (Table 1).

The impact of various independent variables, including polymer concentration, drug concentration, and stirring speed, was significant, as determined by ANOVA. A quadratic Equation (2) relating the particle size with independent parameters was employed as follows.

$$
\begin{gathered}
\text { Particle Size }=+264.33+91.33 \times \mathrm{A}+14.81 \times \mathrm{B}+10.80 \times \mathrm{C}+5.40 \times \mathrm{A} \times \mathrm{B}-0.35 \times \mathrm{A} \times \mathrm{C}+0.095 \times \mathrm{B} \times \mathrm{C}- \\
2.98 \times \mathrm{A} 2+3.62 \times \mathrm{B} 2-1.39 \times \mathrm{C} 2
\end{gathered}
$$

Results revealed that formulations with $0.05 \%$ CRG gave smaller size particles than formulations containing $0.06 \%$ and $0.07 \%$. Formulations N4, N10, N11, and N17 exhibited smaller particle sizes, 162.75, 156.78, 176.68, and $188.32 \mathrm{~nm}$, respectively, due to a lower polymer concentration used, providing fewer binding sites for the crosslinker. Formulations N1, N3, N7, and N15 exhibited large particle sizes, $342.45 \mathrm{~nm}, 332.29 \mathrm{~nm}, 362.43 \mathrm{~nm}$, and $378.0 \mathrm{~nm}$, respectively, due to an increase in the CRG concentration. A substantial increase in CS/CRG percentage is the indicator of larger particle sizes. This is quite reasonable, as CRG is a bulky polymer and, therefore, larger quantities $(0.07 \%)$ are directed to the enlargement of particles [41]. As the percentage of the loaded drug changed from $30 \%$ to $50 \%$, the particle size increased significantly $(p<0.05)$ (Table 2 and Figure 5); accordingly, a high amount of drug-loaded nanoparticles corresponded with large particle size. The reason is that a high amount of drug during the complex formation caused the formation of the gap between CS, CRG, and TPP and decreased CS/CRG/TPP interaction; hence, large-sized particles were produced [42]. The effect of stirring speed was determined by varying the speed between 600 and $900 \mathrm{rpm}$, and it was found to be significant $(p<0.05)$. Smaller particle size was observed at slow stirring, while under vigorous shaking, largersized particles were formed. Size reduction is credited to the cross-linking effect; gentle stirring increased the condensation of polymeric chains, and successively smaller particles were produced. The stirring speed and particle size (Y1) were directly related (Figure 5). Owing to high shear energy and rapidity, the viscosity of the solution increased, which 
contributed to the aggregation of the smaller particles into larger-sized particles [43,44]. Some deviations in size distribution were observed due to the influence of oppositely charged polyions in the complex formation process throughout the formation of NPs [45].

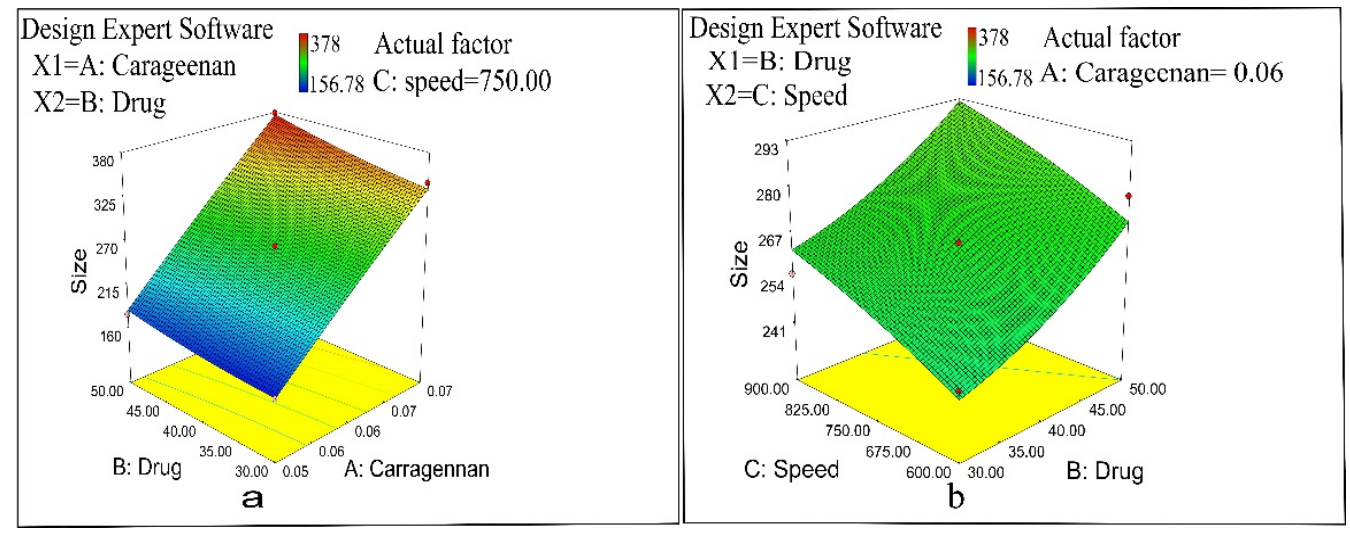

Figure 5. (a) Influence of polymer concentration and drug concentration on particle size and (b) influence of drug concentration and speed on particle size.

\subsection{Ex Vivo Permeation Study}

Fabricated CS/CRG nanoparticles displayed a sustained permeation of NAP for $48 \mathrm{~h}$. Ex vivo permeation pattern was biphasic; initially, fast permeation of NAP was noticed in the first $2 \mathrm{~h}$, and afterward, slow and sustained drug permeation for $48 \mathrm{~h}$ was observed. Percentage cumulative drug permeation of all formulations (N1-N19) is provided in Table 1. The initial fast permeation from nanoparticles was conceivably owing to drug adsorption on the nanoparticles' surfaces; however, as time proceeds, NAP may persistently permeate the polymer matrix (Figure 6). Consequently, the polymer matrix's erosion to hydration showed higher permeability and flux than the NAP control gel [37].

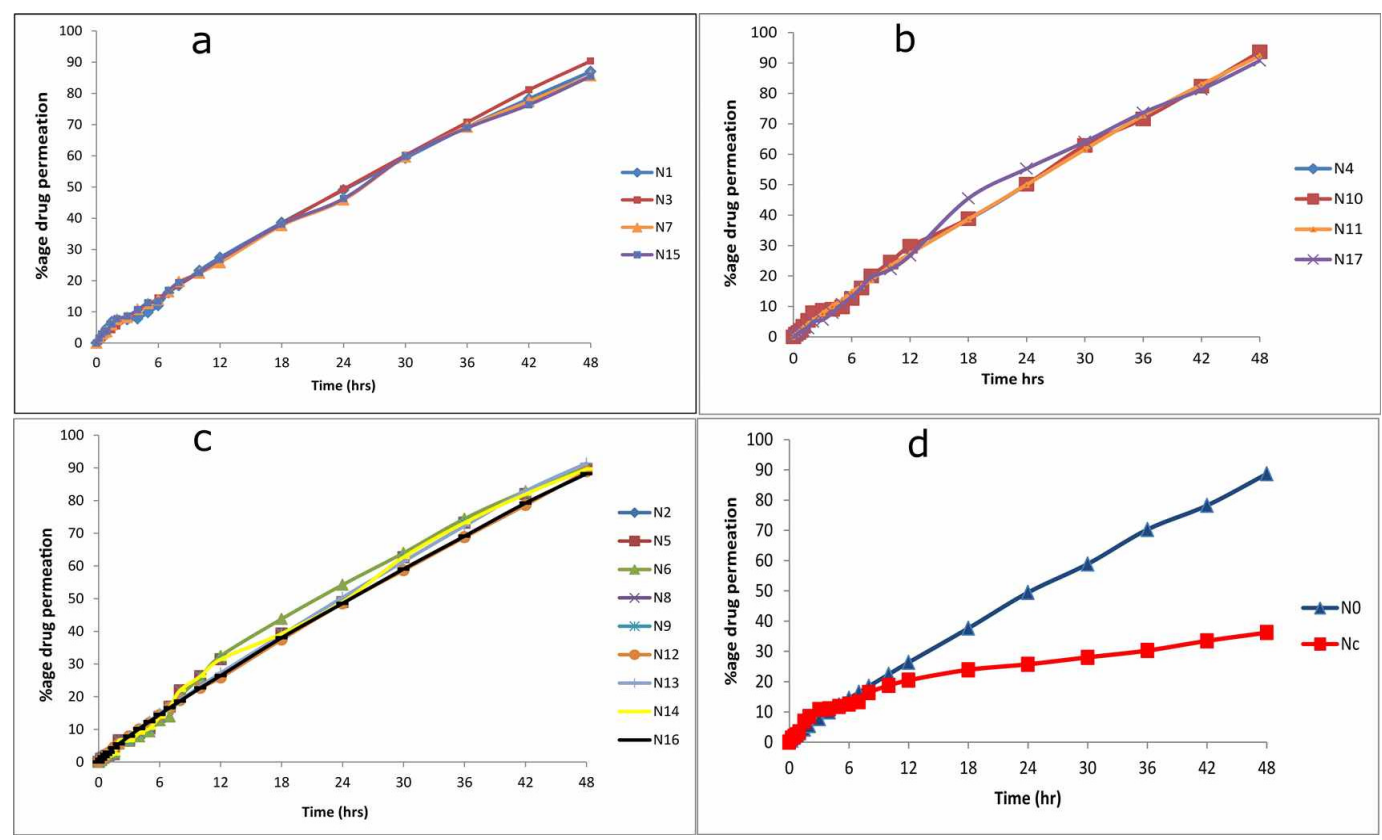

Figure 6. (a) Drug permeation percentage of formulation with $0.05 \%$ of carrageenan; (b) with $0.06 \%$ carrageenan; (c) with 0.07\% carrageenan; (d) optimized formulation (No) containing Carbopol 940 gel and control formulation (Nc) containing Carbopol 940 gel through FT rat skin.

A quadratic equation relating permeation with independent variables was: 


$$
\begin{gathered}
\text { Permeation }=+89.66-2.70 \times \mathrm{A}-0.55 \times \mathrm{B}-1.51 \times \mathrm{C}-0.13 \times \mathrm{A} \times \mathrm{B}-0.45 \times \mathrm{A} \times \mathrm{C}+0.12 \times \mathrm{B} \times \mathrm{C}+ \\
0.13 \times \mathrm{A} 2-0.26 \times \mathrm{B} 2+0.32 \times \mathrm{C} 2
\end{gathered}
$$

Ex vivo studies revealed that the permeation of drug nanoparticles into the skin was within the range of $85.47-93.66 \%$. Figure 7 and Table 2 reveal significantly $(p<0.05)$ slower drug permeation for cross-linked NPs prepared at higher CRG concentration due to a higher degree of cross-linking. Furthermore, increasing the concentration of CRG (kappa) led to a larger particle size with a small surface area. Drug permeation from the nanoparticles was typically reliant on the loaded drug amount. Drug permeation was higher in the NPs of lesser drug entrapment efficiency. However, drug concentration had an insignificant effect $(p>0.05)$ on the nanoparticles' drug permeation. Results specify that drug permeation was independent of the quantity of drug entrapped in the formulation. Drug permeation was slower and significant $(p<0.05)$ for nanoparticles prepared by increasing the stirring speed from 600 to $900 \mathrm{rpm}$ because small particle size has a large surface area for the permeation of the drug [37,46,47].

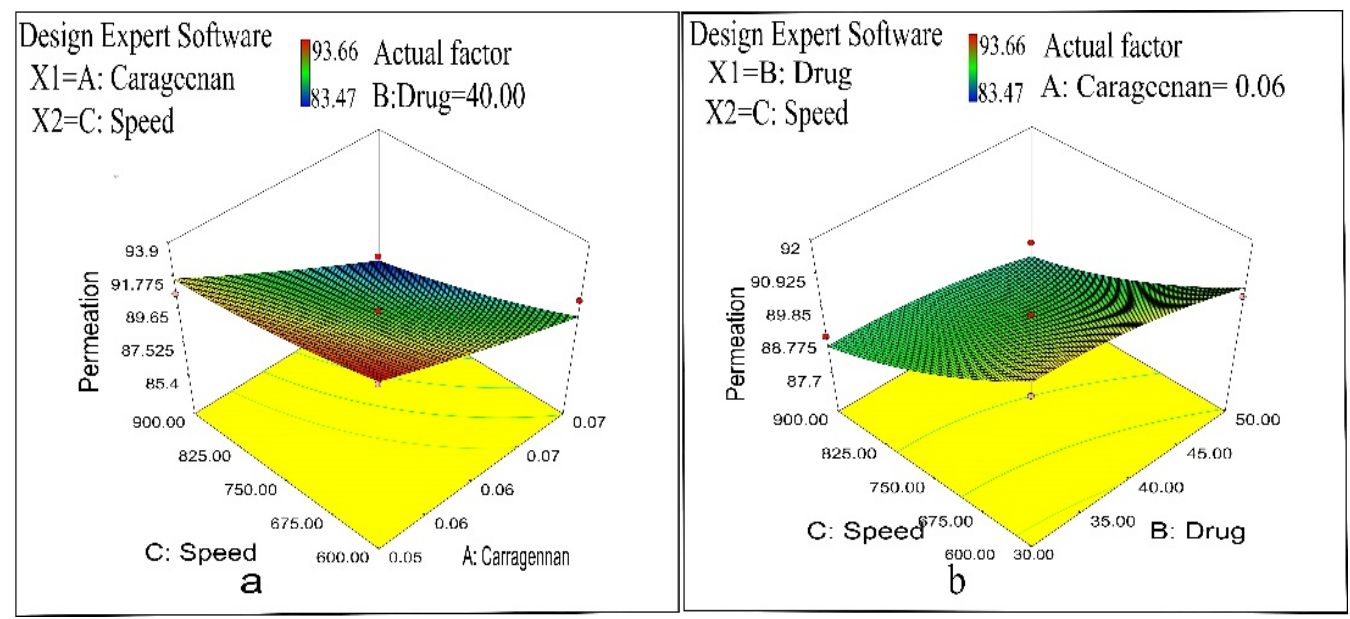

Figure 7. (a) Influence of polymer concentration and stirring speed on drug permeation percentage. (b) Effect of drug concentration and stirring speed on drug permeation percentage.

The cumulative drug permeation percentage from all formulations in descending order is:

$\mathrm{N} 15>\mathrm{N} 7>\mathrm{N} 3>\mathrm{N} 1>\mathrm{N} 6>\mathrm{No}>\mathrm{N} 9>\mathrm{N} 14>\mathrm{N} 5>\mathrm{N} 2>\mathrm{N} 8>\mathrm{N} 12>\mathrm{N} 13>\mathrm{N} 16>$ $\mathrm{N} 11>\mathrm{N} 17>\mathrm{N} 10>\mathrm{N} 4>\mathrm{N} 18>\mathrm{N} 19$.

\subsection{Characterization of Carbopol $940 \mathrm{Gel}$}

2.4.1. Appearance, Spreadability, $\mathrm{pH}$, Viscosity, and Drug Content

The NAP-loaded nanoparticle gel formulations were examined visually for their color and spreadability. All NAP-loaded, NP-containing gels were transparent with a clear appearance and a smooth, homogenous texture. All gel formulations were easily spreadable with low shear force. All the formulation results shown in Table 3 indicate that all the polymers produced good gel spreadability by a small amount of shear force [48]. All NAP-loaded, nanoparticle-containing gel formulations had a $\mathrm{pH}$ in the acceptable range of 6.2-6.8 to avoid skin irritation [49]. Rheological studies of the NAP-loaded, nanoparticlecontaining gel were performed, and results revealed that the viscosity of all formulations was in the range of $5102-5458 \mathrm{cps}[37,50]$. The drug content in all the gel preparations was in the range of $85 \%$ to $96 \%$, which is an acceptable range for optimized therapeutic activity [51]. Results of all these evaluation parameters are shown in Table 3. 
Table 3. Evaluation of naproxen-loaded, CS/CRG-nanoparticle-containing gel.

\begin{tabular}{|c|c|c|c|c|c|c|}
\hline $\begin{array}{c}\text { Formulation } \\
\text { Code }\end{array}$ & $\begin{array}{l}\text { Appearance and } \\
\text { Homogeneity }\end{array}$ & $\mathrm{pH}$ & $\begin{array}{l}\text { Viscosity } \\
\quad \text { (cps) }\end{array}$ & $\begin{array}{c}\text { Spreadability } \\
(\mathrm{cm})\end{array}$ & $\underset{(\%)}{\text { Drug Content }}$ & $\begin{array}{l}\text { Skin } \\
\text { Irritation } \\
\text { Score }\end{array}$ \\
\hline N1 & +++ & 6.8 & 5450 & 3.2 & 92 & 0 \\
\hline N2 & +++ & 6.4 & 5325 & 3.6 & 89 & 1 \\
\hline N3 & +++ & 6.7 & 5455 & 2.8 & 94 & 0 \\
\hline N4 & +++ & 6.8 & 5272 & 4.9 & 87 & 0 \\
\hline N5 & +++ & 6.4 & 5328 & 3.5 & 88 & 1 \\
\hline N6 & +++ & 6.5 & 5335 & 2.4 & 92 & 1 \\
\hline N7 & +++ & 6.8 & 5458 & 2.6 & 93 & 0 \\
\hline N8 & +++ & 6.4 & 5321 & 3.6 & 90 & 1 \\
\hline N9 & +++ & 6.4 & 5332 & 3.7 & 90 & 1 \\
\hline N10 & +++ & 6.2 & 5283 & 4.6 & 87 & 1 \\
\hline N11 & +++ & 6.2 & 5296 & 4.4 & 88 & 1 \\
\hline N12 & +++ & 6.3 & 5340 & 3.3 & 89 & 1 \\
\hline N13 & +++ & 6.4 & 5338 & 3.4 & 90 & 1 \\
\hline N14 & +++ & 6.4 & 5330 & 3.5 & 93 & 1 \\
\hline N15 & +++ & 6.6 & 5466 & 2.9 & 95 & 0 \\
\hline N16 & +++ & 6.3 & 5345 & 3.7 & 92 & 1 \\
\hline N17 & +++ & 6.2 & 5218 & 4.2 & 91 & 1 \\
\hline N18 & +++ & 6.4 & 3200 & 2.6 & 85 & 1 \\
\hline N19 & +++ & 6.3 & 5102 & 2.2 & 87 & 1 \\
\hline $\mathrm{No}$ & +++ & 6.5 & 5040 & 2.3 & 93 & 0 \\
\hline
\end{tabular}

\subsubsection{Skin Irritation Studies}

Skin irritation studies were completed to find the dermal toxicity of all developed formulations and control gel. All the gel preparations showed a Draize score of up to 1, i.e., slight erythema (light pink), indicating the tolerability and lower irritation potential for topical delivery [52] (Table 3).

\subsubsection{Stability Studies for NAP-Loaded Gel}

According to ICH norms, the study of the formulated gel preparations' accelerated stability was performed at different temperature conditions. Stability data of formulations at $\left(4 \pm 1^{\circ} \mathrm{C}\right)$ exhibited good stability behavior regarding $\mathrm{pH}$, viscosity, appearance, spreadability, and percentage of drug content. Formulations at different temperatures (room temperature and accelerated temperature) became unstable [53].

\subsection{Kinetics of Drug Permeation}

The value of the correlation coefficient was observed for zero-order, first-order, and Higuchi models, and the value of " $n$ " exponent in the Korsmeyer-Peppas model was also applied (Table 4). A comparison of calculated values indicated that the zero-order model was the best fit compared to the first-order model in all formulations. A molecular diffusion release pattern was observed after fitting the data to the Higuchi model. In the KorsmeyerPeppas model, the diffusional exponent " $n$ " demonstrated the anomalous (non-Fickian) mechanism of drug permeation from the spherical nanoparticulate matrix $[54,55]$.

The results of the drug permeation through full-thickness rat skin confirmed that NAP was released from the formulation, permeated through the FT rat skin, and could permeate through human skin [56]. 
Table 4. Kinetic parameters of ex vivo permeation studies.

\begin{tabular}{|c|c|c|c|c|c|c|c|c|}
\hline \multirow{2}{*}{ Code } & \multicolumn{2}{|c|}{ Zero-Order } & \multicolumn{2}{|c|}{ First-Order } & \multicolumn{2}{|c|}{ Higuchi Model } & \multicolumn{2}{|c|}{ Korsmeyer-Peppas Model } \\
\hline & $\mathrm{R}^{2}$ & $\mathbf{K}$ & $\mathbf{R}^{2}$ & $\mathbf{K}$ & $\mathbf{R}^{2}$ & $\mathbf{K}_{\mathbf{H}}$ & $\mathbf{R}^{2}$ & $n$ \\
\hline N1 & 0.9899 & 1.922 & 0.9818 & 0.030 & 0.8877 & 10.130 & 0.9976 & 0.869 \\
\hline N2 & 0.9872 & 2.008 & 0.9808 & 0.033 & 0.8890 & 10.594 & 0.9963 & 0.859 \\
\hline N3 & 0.9942 & 1.971 & 0.9782 & 0.031 & 0.8844 & 10.365 & 0.9999 & 0.884 \\
\hline N4 & 0.9921 & 2.020 & 0.9741 & 0.033 & 0.8834 & 10.629 & 0.9980 & 0.883 \\
\hline N5 & 0.9872 & 2.008 & 0.9808 & 0.033 & 0.8890 & 10.594 & 0.9963 & 0.859 \\
\hline N6 & 0.9851 & 2.049 & 0.9800 & 0.034 & 0.8824 & 10.790 & 0.9935 & 0.865 \\
\hline N7 & 0.9877 & 1.901 & 0.9833 & 0.030 & 0.8979 & 10.065 & 0.9986 & 0.846 \\
\hline N8 & 0.9872 & 2.008 & 0.9808 & 0.033 & 0.8890 & 10.594 & 0.9963 & 0.859 \\
\hline N9 & 0.9872 & 2.008 & 0.9808 & 0.033 & 0.8890 & 10.594 & 0.9963 & 0.859 \\
\hline N10 & 0.9922 & 2.025 & 0.9739 & 0.033 & 0.8830 & 10.649 & 0.9980 & 0.884 \\
\hline N11 & 0.9947 & 2.015 & 0.9753 & 0.032 & 0.8825 & 10.586 & 0.9999 & 0.889 \\
\hline N12 & 0.9933 & 1.928 & 0.9809 & 0.031 & 0.8872 & 10.151 & 0.9999 & 0.877 \\
\hline N13 & 0.9938 & 2.008 & 0.9773 & 0.032 & 0.8853 & 10.562 & 0.9999 & 0.881 \\
\hline N14 & 0.9872 & 2.008 & 0.9808 & 0.033 & 0.8890 & 10.594 & 0.9963 & 0.859 \\
\hline N15 & 0.9859 & 1.897 & 0.9853 & 0.030 & 0.9018 & 10.060 & 0.9986 & 0.835 \\
\hline N16 & 0.9923 & 1.933 & 0.9822 & 0.031 & 0.8903 & 10.191 & 0.9999 & 0.868 \\
\hline N17 & 0.9876 & 2.036 & 0.9786 & 0.033 & 0.8774 & 10.693 & 0.9941 & 0.880 \\
\hline N18 & 0.9996 & 1.625 & 0.9779 & 0.023 & 0.8519 & 8.433 & 0.9998 & 0.976 \\
\hline N19 & 0.9981 & 1.366 & 0.9859 & 0.018 & 0.8451 & 7.100 & 0.9983 & 0.977 \\
\hline No & 0.9927 & 1.936 & 0.9818 & 0.031 & 0.8884 & 10.197 & 0.9998 & 0.873 \\
\hline
\end{tabular}

\subsection{Toxicity Study in Rabbits}

Histopathological, biochemical, and hematological studies were performed for the determination of toxicity in the rabbit model. After 14 days of acute oral toxicity studies, the results of various parameters of biochemical, hematological, and weight variation studies in Group I (control) and Group II (treatment) are reported in Table 5. The results of the biochemical and hematological analyses of naproxen-loaded, CS/CRG-nanocarrier-based gel (Group II) presented insignificant changes in comparison to the control group. Histopathological evaluation within organs showed the non-toxic effect of CS/CRG nanocarriers (Figure 8). Seven vital organs, namely, the heart, intestine, kidney, liver, lungs, spleen, and liver, were evaluated, which show the absence of lesions, distortion, and no signs of toxicity at the cellular level (Table 5). Briefly, the acute oral toxicity study predicted that fabricated CS/CRG nanocarriers are useful as effective drug delivery vehicles due to their wide applications through various routes.

Table 5. Different biochemical, hematological, and weight variation studies in Group I (control) and Group II (treatment).

\begin{tabular}{ccc}
\hline Parameter/Test & Group I (Control) & Group II (Treatment) \\
\hline & Biochemical Parameters & $146.02 \pm 2.50$ \\
\hline AST $/$ SGOT $(\mathrm{IU} / \mathrm{L})$ & $144.23 \pm 2.0$ & $0.88 \pm 0.09$ \\
\hline Creatinine $(\mathrm{mg} / \mathrm{dL})$ & $0.75 \pm 0.11$ & $56 \pm 2.04$ \\
\hline Triglycerides $(\mathrm{mg} / \mathrm{dL})$ & $57 \pm 3.11$ & $60.08 \pm 5.10$ \\
\hline Total cholesterol $(\mathrm{mg} / \mathrm{dL})$ & $62.31 \pm 3.76$ & $3.43 \pm 0.03$ \\
\hline Serum uric acid $(\mathrm{mg} / \mathrm{dL})$ & $3.21 \pm 0.02$ & $14.76 \pm 2.32$ \\
\hline Serum urea $(\mathrm{mg} / \mathrm{dL})$ & $12.56 \pm 3.04$ & \\
\hline
\end{tabular}


Table 5. Cont.

\begin{tabular}{|c|c|c|}
\hline Parameter/Test & Group I (Control) & Group II (Treatment) \\
\hline \multicolumn{3}{|c|}{ Hematological Parameters } \\
\hline Hemoglobin $\mathrm{Hb}(\mathrm{g} / \mathrm{dL})$ & $13.21 \pm 0.32$ & $13.48 \pm 0.41$ \\
\hline Red blood cells $(\mathrm{RBCs}) \times 10^{6} / \mathrm{mm}^{3}$ & $6.12 \pm 0.51$ & $5.66 \pm 0.61$ \\
\hline White blood cells $($ WBCs $) \times 10^{9} / \mathrm{L}$ & $6.62 \pm 0.02$ & $6.77 \pm 0.40$ \\
\hline Platelets $\times 10^{9} / \mathrm{L}$ & $4.05 \pm 2.05$ & $4.16 \pm 2.06$ \\
\hline Neutrophils (\%) & $55.80 \pm 4.05$ & $57.55 \pm 5.11$ \\
\hline Lymphocytes (\%) & $38.30 \pm 1.08$ & $39.21 \pm 1.02$ \\
\hline Monocytes (\%) & $3.60 \pm 0.11$ & $3.65 \pm 0.21$ \\
\hline Mean corpuscular volume (\%) & $83.66 \pm 2.10$ & $84.84 \pm 2.40$ \\
\hline Mean corpuscular hemoglobin (pg/cells) & $23 \pm 3.05$ & $24 \pm 2.25$ \\
\hline Mean corpuscular hemoglobin concentration (\%) & $33.30 \pm 2.21$ & $33.92 \pm 1.41$ \\
\hline \multicolumn{3}{|c|}{ Rabbit Organ Weights } \\
\hline Heart & $4.33 \pm 0.20$ & $4.40 \pm 0.16$ \\
\hline Kidney & $12.33 \pm 0.21$ & $13.75 \pm 0.81$ \\
\hline Liver & $7.22 \pm 2.01$ & $8.22 \pm 2.11$ \\
\hline Lungs & $9.22 \pm 0.38$ & $9.25 \pm 0.51$ \\
\hline Spleen & $1.12 \pm 0.11$ & $1.13 \pm 0.14$ \\
\hline Stomach & $12.22 \pm 0.41$ & $13.01 \pm 0.70$ \\
\hline
\end{tabular}

Note. All values are expressed as mean $\pm S D(n=3)$.

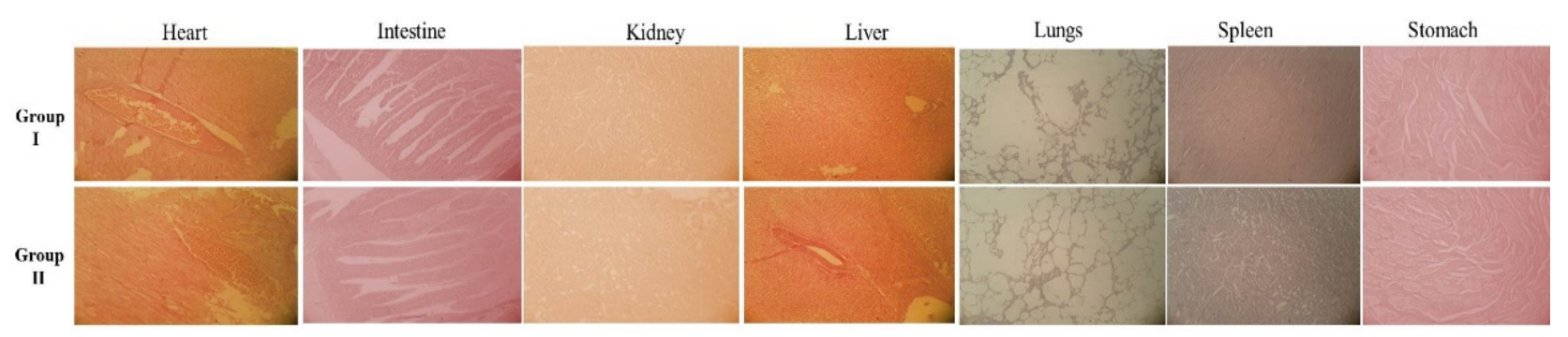

Figure 8. Histopathological examination of different organs of Group I (control group) and Group II (treatment group) of rabbits.

\subsection{Optimization}

2.7.1. Evaluation of Optimized Formulation of Naproxen-Loaded CS/CRG Nanoparticles

An optimized formulation was developed by applying the independent variables suggested by Design-Expert software (polymer 0.07\%, drug 30\%, and stirring speed $900 \mathrm{rpm}$ ). The values of entrapment efficiency, particle size, and drug permeation (\%), as predicted by Design-Expert, were $97.43 \%, 345.015 \mathrm{~nm}$, and $85.735 \%$, respectively. Optimized formulation revealed an entrapment efficiency of $95.26 \% \pm 3.23$, the particle size of $355.7 \pm 79.8 \mathrm{~nm}$, and the zeta potential of $+25 \pm 3.1 \mathrm{mV}$, while $88.66 \%$ drug permeated from the nanoparticlecontaining gel following a 48 -h period. Therefore, the optimized nanoparticle-containing gel preparation is anticipated to sustain NAP permeation for $48 \mathrm{~h}$ (Table 6).

2.7.2. Evaluation of Optimized Formulation of Naproxen-Loaded, CS/CRG-NanoparticleContaining Carbopol 940 (Ca-940) Gel

The optimized formulation of NAP-loaded nanoparticles was incorporated into $0.1 \%$ Carbopol 940 gel and used for further characterization. Stability studies were performed to check the interaction between the drug and Carbopol gel, which was necessary for obtaining an optimized formulation with an optimized therapeutic effect (Table 6). 
Table 6. Evaluation of optimized formulation of naproxen-loaded CS/CRG nanoparticles and stability study of optimized formulation.

\begin{tabular}{|c|c|c|c|c|c|}
\hline \multicolumn{6}{|c|}{ Optimized Formulation (No) } \\
\hline Parameters & $\begin{array}{c}\text { Entrapment } \\
\text { Efficiency (\%) }\end{array}$ & Particle Size (nm) & PDI & Zeta Potential (mV) & $\begin{array}{c}\text { Cumulative Drug } \\
\text { Permeation }(\%)\end{array}$ \\
\hline $\begin{array}{l}\text { Predicted variables by } \\
\text { design expert }\end{array}$ & 97.43 & 345.015 & - & - & 85.7359 \\
\hline Experimental values & $95.26 \pm 3.23$ & 355.7 & 0.381 & $+25 \pm 3.1$ & 88.66 \\
\hline \multicolumn{6}{|c|}{ Stability study of optimized formulation } \\
\hline Time & Appearance & $\mathrm{pH}$ & Viscosity (cps) & Spreadability (cm) & Drug content $(\%)$ \\
\hline Day 0 & ++ & 6.78 & 5483 & 2.82 & 94 \\
\hline Day 30 & ++ & 6.74 & 5496 & 2.87 & 92 \\
\hline Day 60 & ++ & 6.76 & 5509 & 3.20 & 90 \\
\hline Day 90 & ++ & 6.66 & 5483 & 3.27 & 88 \\
\hline
\end{tabular}

The ex vivo drug permeation of the optimized nanoparticle-containing gel preparation was compared with the control gel. Ex vivo drug discharge of NAP from the optimized nanoparticle-containing gel formulation presented improved drug permeation (88.66\%) through the epidermis compared with the control gel (36.19\%), as depicted in Figure 6, as the chitosan polymer in an NP formulation enhances permeation [57]. For the absolute permeation of nanoparticles through human skin, the nanoparticle size should be less than $400 \mathrm{~nm}$ for drug delivery applications [58]. Hence, the synthesized CS/CRG NPs are suitable for loading on and permeating NAP into the human skin.

The optimized nanoparticle-containing gel preparation is anticipated to sustain NAP permeation for $48 \mathrm{~h}$ (Table 6). Ex vivo drug permeation data of the optimized formulation (No) were exposed to kinetic modeling, and they demonstrated that the permeation of NAP from optimized nanoparticles follow a non-Fickian mechanism, as confirmed by the value of the diffusional exponent $(n=0.873)$, and followed zero-order kinetics $\left(\mathrm{R}^{2}=0.9927\right)$ better than first-order $\left(\mathrm{R}^{2}=0.9818\right)$.

\subsection{In Vivo Anti-Inflammatory Studies on Rats}

Paw volume increased significantly $(p<0.05)$ in the formalin-induced edema (FIE) model. However, treatment with NAP NP gel reduced the inflammation and reduced paw volume significantly $(p<0.05)$ compared to the NAP control gel (Figure 9). NAP NP gel showed significant inhibition of $36 \%, 57 \%$, and $79 \%$ at 1,3 , and $5 \mathrm{~h}$, respectively. Reduction in paw volume also appeared in the NAP control gel group $(21 \%, 45 \%$, and $59 \%$, respectively) (Table 7). In conclusion, the NAP NP gel has more significant antiinflammatory effects due to enhanced permeation compared to the NAP control gel to treat arthritis. The same results in terms of percentage of inhibition of paw edema were achieved by Cong et al. when they compared the NAP and Indomethacin effects on the induction, duration, and intensity of rat paw edema [59]. Histopathological examination of rat paw tissue (Figure 10) showed increased inflammatory cells, severe edema, loosening of the epithelial layer, and accumulation of collagenous materials. Rats treated with NAP nanoparticle (NP) gel showed mild edema, and most of the inflammatory histological changes were set to normal at the end of the fifth hour (Figure 10D). However, the group treated with the NAP control gel showed marked histological changes (Figure 10C) in the accumulation of collagenous tissues in the deep dermis and infiltration of inflammatory cells compared to the group treated with the NAP NP gel. The NAP NP gel's increased antiinflammatory effects might be due to chitosan/carrageenan's permeation enhancement effects [60]. 


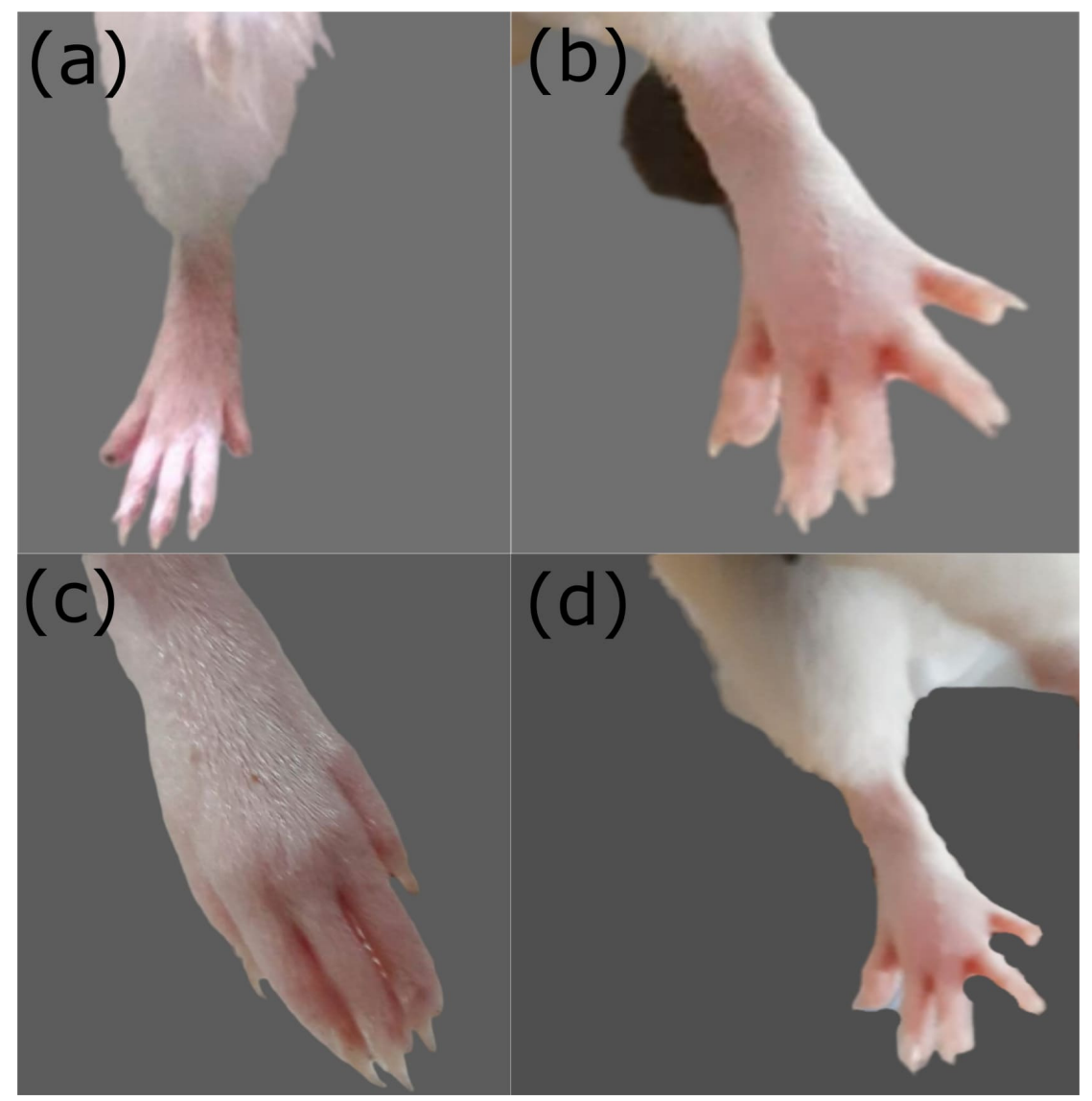

Figure 9. (a) Photograph of control animal rat paw; (b) photograph of formalin-induced rat paw; (c) photograph of NAP-gel-treated rat paw; (d) photograph of control-gel-treated rat paw.

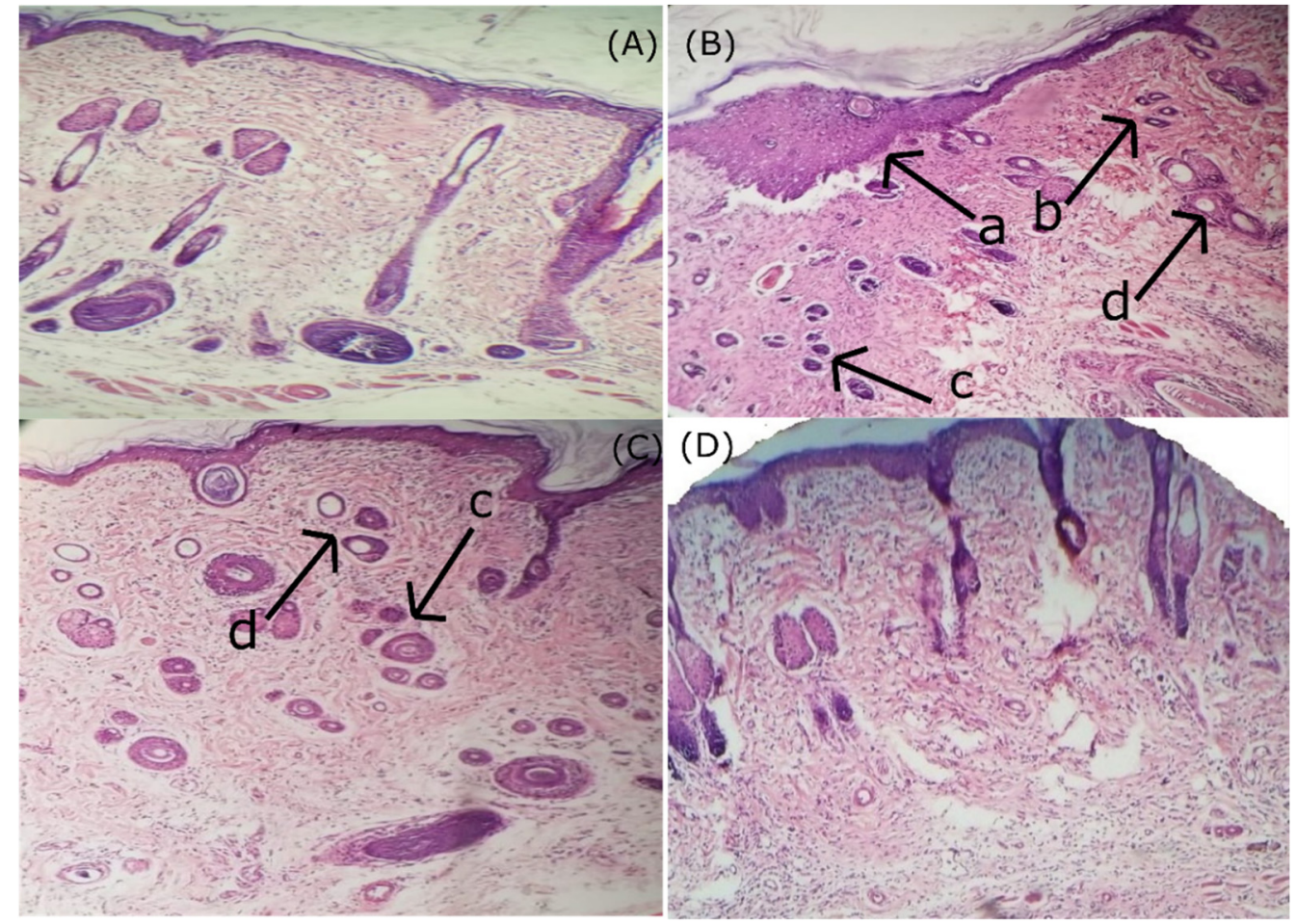

Figure 10. Histopathological study of rat paw tissue; (A) control paw tissue showed normal epidermis, deep dermis, and subcutaneous tissues; (B) (a) group treated with formalin alone showed marked 
hyperkeratosis of skin with epithelial proliferation. (b) Under dermis loosens and is edematous. (c) Deep dermis and subcutaneous tissues show moderate inflammatory cell infiltration. (d) edema, and proliferation of collagenous tissue. (C) (c) FIE + control-gel-treated group shows deep dermis and subcutaneous tissues with mild inflammatory cell infiltration, (d) edema, and proliferation of collagenous tissue. (D) FIE + NAP-gel-treated group showed a marked reduction in the injury to paw tissue. Most of the histological changes were minimized and found negligible as compared to the group treated with formalin alone. (FIE = formalin-induced edema).

Table 7. Percentage inhibition of paw edema after 1,3 , and $5 \mathrm{~h}$ on experimental animals.

\begin{tabular}{cccc}
\hline \multicolumn{4}{c}{ Percentage Inhibition of Paw Edema } \\
\hline Groups & $1 \mathrm{~h}$ & $3 \mathrm{~h}$ & $5 \mathrm{~h}$ \\
\hline FIE & 16 & 16 & 16 \\
\hline Formalin + NAP NP gel & $36 \pm 0.96$ & $57 \pm 0.79$ & $79 \pm 0.85$ \\
\hline Formalin + NAP control gel & $21 \pm 0.76$ & $45 \pm 1.13$ & $59 \pm 1.01$ \\
\hline
\end{tabular}

\section{Materials and Methods}

\subsection{Materials}

Naproxen (PubChem CID: 23681059) was received as a kind gift from Schazoo Laboratories (Pvt.) Ltd. (Karachi, Pakistan). Chitosan (LMW) (PubChem CID: 21896651) and sodium tripolyphosphate (STPP) (PubChem CID: 24455) were purchased from SigmaAldrich (Steinheim, Germany). Carrageenan (k-kappa) (PubChem CID: 11966249) was from CP Kelco, a Huber company. Carbopol 940, ethanol, triethanolamine, and sodium hydroxide were obtained from Sigma-Aldrich (Steinheim, Germany).

\subsection{Methods}

\subsubsection{Design of Experiment (Box-Behnken Design)}

For the evaluation of the influence of different formulation variables on entrapment efficiency, particle size, and drug permeation, the response surface methodology (RSM) was used as a statistical tool and mathematical technique. A 3-factor, 3-level Box-Behnken design (BBD) was used for designing 17 experimental runs (25). Two different formulations were also prepared, one without CRG (N18) and one without STPP (N19), to study the effect of these polymers (Table 8). Carrageenan concentration (X1), drug concentration (X2), and stirring speed $(\mathrm{X} 3)$ were selected as independent process variables, each with three levels: [X1 (0.05\%, 0.06\%, 0.07\%), X2 (30\%, 40\%, 50\%), and X3 (600, 750, and $900 \mathrm{rpm})$ ]. The effect of change in independent variables on dependent variables (i.e., entrapment efficiency (Y1), particle size (Y2), and percentage of cumulative drug permeation (Y3)) was studied using one-way analysis of variance (ANOVA) using Stat-Ease (Design-Expert 9.0.6.2). The following non-linear quadratic equation (Equation (4)) was used to evaluate the significance of each independent variable.

$$
\begin{aligned}
\mathrm{Y}=\beta 0+\beta 1 X 1+ & \beta 2 \mathrm{X} 2+\beta 3 \mathrm{X} 3+\beta 11 \mathrm{X} 21+\beta 22 \mathrm{X} 22+\beta 33 \mathrm{X} 23+\beta 12 \mathrm{X} 1 \mathrm{X} 2+\beta 13 \mathrm{X} 1 \mathrm{X} 3+\beta 23 \mathrm{X} 2 \mathrm{X} 3 \\
& \text { where: } \\
& \mathrm{Y} \text { is the dependent variable; } \\
& \mathrm{X} 1, \mathrm{X} 2 \text {, and } \mathrm{X} 3 \text { are independent variables; } \\
& \beta 1, \beta 2, \text { and } \beta 3 \text { are non-linear coefficients; } \\
& \beta 11, \beta 22 \text {, and } \beta 33 \text { are squares of coefficients; } \\
& \beta 12, \beta 13, \text { and } \beta 23 \text { are the interaction coefficients of this non-linear equation. }
\end{aligned}
$$


Table 8. Experimental parameters based on a Box-Behnken design.

\begin{tabular}{|c|c|c|c|c|c|c|}
\hline Formulation Code & $\begin{array}{c}\text { Naproxen } \\
(\%)\end{array}$ & $\begin{array}{c}\text { Chitosan } \\
(\%)\end{array}$ & $\begin{array}{c}\text { Carrageenan } \\
(\%)\end{array}$ & $\begin{array}{l}\text { STPP } \\
(\%)\end{array}$ & $\begin{array}{l}\text { Stirring Time } \\
\text { (h) }\end{array}$ & $\begin{array}{l}\text { Stirring Speed } \\
(\mathrm{rpm})\end{array}$ \\
\hline N1 & 30 & 0.1 & 0.07 & 0.5 & 1 & 750 \\
\hline N2 & 40 & 0.1 & 0.06 & 0.5 & 1 & 750 \\
\hline N3 & 40 & 0.1 & 0.07 & 0.5 & 1 & 600 \\
\hline $\mathrm{N} 4$ & 30 & 0.1 & 0.05 & 0.5 & 1 & 750 \\
\hline N5 & 40 & 0.1 & 0.06 & 0.5 & 1 & 750 \\
\hline N6 & 50 & 0.1 & 0.06 & 0.5 & 1 & 600 \\
\hline N7 & 40 & 0.1 & 0.07 & 0.5 & 1 & 900 \\
\hline N8 & 40 & 0.1 & 0.06 & 0.5 & 1 & 750 \\
\hline N9 & 40 & 0.1 & 0.06 & 0.5 & 1 & 750 \\
\hline N10 & 40 & 0.1 & 0.05 & 0.5 & 1 & 600 \\
\hline N11 & 50 & 0.1 & 0.05 & 0.5 & 1 & 750 \\
\hline N12 & 30 & 0.1 & 0.06 & 0.5 & 1 & 900 \\
\hline N13 & 30 & 0.1 & 0.06 & 0.5 & 1 & 600 \\
\hline N14 & 40 & 0.1 & 0.06 & 0.5 & 1 & 750 \\
\hline N15 & 50 & 0.1 & 0.07 & 0.5 & 1 & 750 \\
\hline N16 & 50 & 0.1 & 0.06 & 0.5 & 1 & 900 \\
\hline N17 & 40 & 0.1 & 0.05 & 0.5 & 1 & 900 \\
\hline N18 & 40 & 0.1 & 0 & 0.5 & 1 & 750 \\
\hline N19 & 40 & 0.1 & 0.06 & 0 & 1 & 750 \\
\hline No (optimized) & 30 & 0.1 & 0.07 & 0.5 & 1 & 900 \\
\hline
\end{tabular}

\subsubsection{Experimental Method}

In two main steps, nanoparticulate-containing Carbopol gel was formulated.

(A.) Preparation of NAP-loaded CS/CRG nanoparticles

NAP-loaded CS/CRG nanoparticles were fabricated by a polyelectrolyte complexation technique with minor alterations to a previously reported methodology $[24,41]$. Furthermore, ionotropic gelation was performed in the presence of a counter ion, i.e., STPP [61].

CS solution ( $0.1 \%$ ) was prepared by mixing CS in $1 \%$ acetic acid $(v / v)$ and stirring overnight at $40{ }^{\circ} \mathrm{C}$ using a magnetic stirrer. Any undissolved chitosan was removed by filtration. CRG was mixed in distilled water $(10 \mathrm{~mL})$ at $60^{\circ} \mathrm{C}$ using a magnetic stirrer. To fabricate the drug-loaded CS/CRG complex nanoparticles, NAP was mixed in ethanol $(2 \mathrm{~mL}$ ) and added to the CRG solution. NAP concentration in the CRG solution was kept in such a range so that nanoparticles were prepared with $30 \%, 40 \%$, and $50 \%(w / w)$ of drug concentration in the CS solution. Polyelectrolyte complex formation occurred when drugcontaining CRG solutions were incorporated into a CS solution under magnetic stirring for $60 \mathrm{~min}$. Then, CS was polymerized through ionic gelation with STPP. An STTP solution of $0.5 \%(w / v)$ was used as a crosslinker, prepared by dissolution in distilled water. The STPP solution was added dropwise into the drug-containing CS solution under magnetic stirring for $1 \mathrm{~h}$. Freshly prepared nanoparticles were then subjected to centrifugation (Sigma 1-14; Sigma Laborzentrifugen $\mathrm{GmbH}$, Osterode am Harz, Germany) at 12,000 rpm for $40 \mathrm{~min}$. The supernatants were used to find the entrapped drug (\% EE), and nanoparticles were resuspended in $1 \mathrm{~mL}$ of purified water and dried by lyophilization for $48 \mathrm{~h}$. 
(B.) Formation of Carbopol 940 gel containing naproxen-loaded CS/CRG nanoparticles

Carbopol $940(0.1 \%)$ was used as a gelling agent. Ca-940 was mixed in distilled water by continuous stirring at $800 \mathrm{rpm}$ for $1 \mathrm{~h}$ by homogenizer (VELP Scientifica, Usmate Velate, Italy) to form Ca-940 solutions. Gel pH (6.2-6.8) was maintained by using $0.05 \%$ triethanolamine. Optimal viscosity, clear visual appeal, compatibility, and spreadability of a gelling agent with polymers and drugs were the core elements in selecting the gelling agent. Then, $50 \mathrm{mg}$ NAP-containing nanoparticles were accurately measured and mixed thoroughly with the above-mentioned Ca-940 solutions [37].

\subsection{Characterization of Nanoparticles}

\subsubsection{Entrapment Efficiency}

The entrapment efficiency (EE) of the drug in the CS/CRG nanoparticle complex was evaluated using both direct and indirect methods $[62,63]$. Moreover, when the results of both methods were compared, the results were almost the same. In this study, we used an indirect method for the study's convenience, and results were produced for 19 formulations in the manuscript. As described in the methodology, drug incorporation evaluation of naproxen-loaded nanoparticles was performed via centrifugation at 12,000 rpm for $40 \mathrm{~min}$. The supernatant containing unentrapped drug was separated and added into the water obtained after washing. By combining both solutions, the concentration was calculated by taking 3-times UV absorbance at $262.6 \mathrm{~nm}$ [62]. The percentage entrapment efficiency was calculated by using the equation given below.

$\%$ E.E. $=($ Total amount of drug - Unentrapped drug $) /($ Total amount of drug $) \times 100$

\subsubsection{Particle Size, Polydispersity Index, and Zeta Potential Determination}

The particle size, zeta potential, and PDI were determined via the dynamic light scattering (DLS) technique (Zetasizer Nano ZS90, Malvern Panalytical, Malvern, UK). The dried lyophilized nanoparticle powder samples were suspended in distilled water and vortexed before measurement to prevent clumping. Then, a 1-mL nanoparticle dispersion sample was taken and diluted 10 times with deionized water in Zetasizer cuvettes for particle size and zeta potential determination.

\subsubsection{Scanning Electron Microscopy (SEM)}

The nanoparticles' morphology was inspected by scanning electron microscopy (SEM) with a Philips XL30 scanning microscope (JSM-IT-100, JEOL, Japan) at an accelerating $5-10 \mathrm{kV}$ voltage. Before the assessment, NP samples were placed on an electroconductive chip of silicon on top of aluminum stubs, under an argon atmosphere (JSM-5910, JEOL Ltd., Tokyo, Japan) and through a sputter coater. Both formulations ("lyophilized" and "water dispersion") were selected to study the morphological characteristics and appearance. Photomicrographs of coated nanoparticles were taken to reveal their external surface and morphological characteristics [64].

\subsubsection{Fourier Transforms Infrared Spectroscopy (FTIR)}

Fourier transform infrared (FTIR) spectroscopic analysis was used to study the drugpolymer interaction, preferably for compatibility studies [65]. Pure NAP, chitosan (LMW), carrageenan (kappa), drug-polymer physical mixture, and other formulations were analyzed and compared to find any possible interaction between components of the formulation by FTIR (Tensor 27 IR; Bruker, Karlsruhe, Germany). The physical mixture was prepared by geometric mixing of the components in a mortar for $5 \mathrm{~min}$ and then "sieving through 100 mesh size sieves" [66]. Powdered nanoparticles sample were placed on ATR crystal and pressed on the crystal's face by rotating and turning the arm to achieve efficient contact. Scanning was done for $16 \mathrm{~s}$ in the range of $4000-500 \mathrm{~cm}^{-1}$. 


\subsubsection{Powdered X-ray Diffraction (pXRD) Analysis}

Powdered X-ray diffraction (XRD) analysis is an effective tool to analyze the amorphous and crystalline nature of particles and biopolymer electrolytes. The powdered X-ray diffractometry (PXRD) of NAP, CS, CRG, physical mixture, and optimized formulation (No) was recorded by a powder X-ray Diffractometer (JDX 3532; JEOL Ltd., Tokyo, Japan) to analyze the solid-state stability of the components mentioned above. Samples were examined at $2 \theta$ in the range of $10^{\circ}$ to $60^{\circ}$. The sample's X-ray diffraction patterns were detected using the $\mathrm{Cu}$ line as a source of radiation, and a power of $35 \mathrm{kV}$ with a $40 \mathrm{~mA}$ current was supplied.

\subsubsection{Acute Oral Toxicity Study}

As per the guidelines of the Organization for Economic Co-operation and Development (OECD), the toxicity study was designed for polyelectrolyte complex nanoparticles to evaluate the fabricated particles' safety and biocompatibility. According to the guidelines, the animal house environment was maintained, i.e., $40 \%$ relative humidity, and $22{ }^{\circ} \mathrm{C} \pm$ $3{ }^{\circ} \mathrm{C}$ room temperature with a sequence of light and dark cycles. Rabbits were selected as the animal model due to data availability and the recognized pathophysiology; ultimately, the effects on human health can be predicted. All the rabbits were assigned into Group I and Group II, each group having six rabbits $(n=6)$ that were housed in ventilated and cleaned cages. Standard food and water were administered to Group I and taken as the Control group, whereas for Group II (Treatment group), treatment therapy was administered. The toxicity studies were conducted after approval (08-2020/PAEC) from the Pharmacy Animal Ethics Committee (PAEC), The Islamia University of Bahawalpur. Animals in both groups were keenly observed for 15 days, and then samples were collected for the evaluation of blood chemistry [67].

\subsubsection{Characterization of Naproxen-Loaded, CS/CRG-Nanoparticle-Containing Ca-940 Gel}

The above-formulated NAP-loaded CS/CRG-nanoparticle-containing Ca-940 gel was subjected to evaluation for the following parameters:

Appearance, $\mathrm{pH}$, Viscosity, and Spreadability

All prepared NAP nanoparticle-containing gel preparations were studied for their color, clarity, homogeneity, and presence of lumps by visual inspection [48]. A digital $\mathrm{pH}$ meter (inoLab; Xylem Analytics, Germany) was used for the determination of $\mathrm{pH}$ of the Ca-940 gel formulations. NAP nanoparticle-containing gels were transferred to a graduated beaker and made a 50-milliliter final volume with distilled water. The freshly prepared gel formulations were measured by using a digital $\mathrm{pH}$ meter immersed entirely into the gel system until a constant reading was achieved. Each formulation's $\mathrm{pH}$ was measured in triplicate by calculating the average $[68,69]$. The viscosity of the NAP gel was measured at $25^{\circ} \mathrm{C}$ using a Brookfield RST Cone Plate Rheometer with spindle CP 62 at $4 \mathrm{rpm}$ for $50 \mathrm{~s}$ [70].

Spreadability is one of the most critical parameters of which to evaluate the ideal quality, as the spreading value is critical for the gel formulation's therapeutic efficacy. Briefly, $0.5 \mathrm{~g}$ of gel formulation was placed on a glass plate within a pre-marked circle with a diameter of $1 \mathrm{~cm}$, over which a second glass plate was placed to measure the spreadability of the NAP-loaded gel. A weight of $100 \mathrm{~g}$ was allowed to rest on the upper glass plate for $5 \mathrm{~min}$. The gel formulations' spreadability was measured in triplicate by calculating an increase in diameter [52].

\section{Drug Content}

A total of $100 \mathrm{~mL}$ of ethanolic phosphate buffer (EPB) was prepared, and a sample of gel containing NAP nanoparticles $(100 \mathrm{mg})$ was dispersed in it. For the complete solubilization of the drug into EPB, a mechanical shaker (IKA-Werke, Germany) was used 
for $4 \mathrm{~h}$. After filtration, the UV absorbance of the sample was taken at $262.6 \mathrm{~nm}$ by using a phosphate buffer (pH 7.4) as a blank [71].

Skin Irritation Studies for Naproxen-Loaded Gel

For the evaluation of the skin irritation potential of NAP nanoparticle-containing gels, the Draize patch test was performed. Albino Wistar rats $(200 \pm 0.25 \mathrm{~g})$ of any gender were supplied by Islamia University Animal Research Centre Bahawalpur, Pakistan, and were individually housed in the animal house with a supply of food and water. Twenty rats were separated into two groups $(n=2)$ : group 1 received all NAP formulations containing nanoparticle gel, and group 2 received pure NAP (control gel). A precise area on the back of the rats was shaven $24 \mathrm{~h}$ before the formulation application. A required amount of gel (equal to $5 \mathrm{mg}$ naproxen) was applied to the rats' hair-free skin. The test site remained intact for $48 \mathrm{~h}$, then the gel was detached, and the resulting skin reactions were observed on 48th, 72nd, and 96th hour. An erythema score was given from 0 to 4, conditional on the degree of erythema [72].

\section{Stability Studies}

Stability studies (accelerated stability studies) for NAP nanoparticle-containing gels were performed by placing the formulations at different stability conditions. The formulations of nanoparticles were divided into four batches; one batch was kept at room temperature $27 \pm 1{ }^{\circ} \mathrm{C}$, the second at $4 \pm 1{ }^{\circ} \mathrm{C}$, the third at $37 \pm 1{ }^{\circ} \mathrm{C}$, and the fourth at $45 \pm 1{ }^{\circ} \mathrm{C}$ for 3 months. At weekly intervals, the absorbance of samples was taken at $262.6 \mathrm{~nm}$ using a phosphate buffer (pH-7.4), and physicochemical properties were estimated [73].

\subsection{Evaluation of Ex Vivo Drug Permeation Study}

\subsubsection{Preparation of Full-Thickness (FT) Rat Skin}

The experiment was approved by the Pharmacy Research Ethics Committee and conducted according to protocol. The skin was obtained from the albino rat (weight: 200-400 g). An FT rat skin was taken out by removing the fat using a surgical scalpel, adhering to the dermis side of the skin. As a final point, the skin was washed with a phosphate buffer (7.4), kept in aluminum foil, stored at $-20^{\circ} \mathrm{C}$, and was used within a week [74].

\subsubsection{Ex Vivo Permeation Studies by Using Franz Diffusion Cells}

Franz diffusion cells were used to perform the skin permeation studies for $48 \mathrm{~h}$ by using FT rat skin. The skin sample was kept in a phosphate buffer solution for $2 \mathrm{~h}$ before the experiment provided optimal skin hydration. The receptor chamber was filled with a phosphate buffer of $\mathrm{pH} 7.4$, and the FT rat skin was mounted on a diffusion cell. The whole assembly was kept over a magnetic stirrer, and the temperature was maintained at $32 \pm 0.5^{\circ} \mathrm{C}$. After maintaining the skin, NAP nanoparticle-containing gel equal to $5 \mathrm{mg}$ NAP was spread over the skin and covered to avoid solvent evaporation. At a specific interval, a sample of $200 \mu \mathrm{L}$ was withdrawn from the lower compartment and was replaced with fresh medium. UV spectrophotometric analyses were performed at $262.6 \mathrm{~nm}$ [75]. The ex vivo drug permeation of optimized nanoparticle gel (No) was compared with the control gel using ANOVA. The control gel was prepared by adding pure drug (NAP $50 \mathrm{mg}$ ) into the Carbopol 940 gel $(100 \mathrm{mg}$ ). Additionally, $10 \mathrm{mg}$ of control gel (containing $5 \mathrm{mg}$ of NAP) was used for experimental purposes and compared with the optimized nanoparticle-containing gel equal to $5 \mathrm{mg}$ of NAP. Drug permeation was evaluated by using the following formula:

Percent drug permeated $=($ Quantity of drug permeated at time $`) /($ quantity of drug-loaded in nanoparticles $) \times 100$

The percentage of drug permeation through FT rat skin was plotted between the time and flux (penetration rate), which was determined. 


\subsection{In Vivo Anti-Inflammatory Studies in Rats}

\subsubsection{Animals}

Albino rats of $150+10 \mathrm{~g}$ were bred in the animal house of the Pharmacy department of The Islamia University of Bahawalpur, Pakistan, and were fed on a standard laboratory diet with water. Polypropylene cages were used for rats by maintaining the room temperature at $25+1{ }^{\circ} \mathrm{C}$, a photoperiod $(12: 12 \mathrm{~h})$ light and dark cycle, and humidity at $55-60 \%$. The animal trial studies were approved by the Pharmacy Animal Ethics Committee (08-2020/PAEC) at The Islamia University of Bahawalpur.

\subsubsection{Treatment Protocol}

Animals were distributed into 4 groups ( 6 each) and treated accordingly: normal control, formalin, formalin + NAP NP gel $(15 \mathrm{mg} / \mathrm{kg})$, and formalin + NAP control gel. Inflammation was induced by administering intradermal formalin $(0.1 \mathrm{~mL}$ of $2 \% v / v)$ in each rat's right hind paw on the first and third days of the experiment. A paw edema meter was used to measure the paw volume 1,3 , and $5 \mathrm{~h}$ after treatment. For the calculation of the degree of swelling in the paw and the inhibition rate of edema, the following formula was used

$$
\text { Percentage inhibition }=1-\mathrm{VT} / \mathrm{VC} \times 100
$$

where VT and VC are the paw volume of the treatment and control group, respectively. The rats were sacrificed by decapitation at the end of the 7 days. After that, a histopathological evaluation of the samples was performed.

\subsection{Histopathology Analysis}

The right paw tissues were removed, fixed in $10 \%$ formalin, and handled with paraffin embedding. Tissue samples of $3 \mathrm{~mm}$ thickness were selected and placed on the slides. Tissues stained with hematoxylin for investigating under a light microscope for histopathological changes [76].

\subsection{Statistical Analysis}

Statistical analysis was applied to the data in order to evaluate the influence of independent variables on the response variables. Design-Expert software (9.0.6.2) was selected as a statistical tool to perform statistical analysis. For the evaluation of the significance of each of the independent variables, an ANOVA test was applied. A value of " $p$ " less than 0.05 was considered significant.

\subsection{Model Dependent Permeation Kinetic Analysis}

For the determination of the order and mechanism of drug permeation, different kinetic models were applied to ex vivo permeation data. Regression analysis was applied to the ex vivo permeation data, and a coefficient of zero-order as the cumulative amount of drug permeates vs. time [77], first-order as the cumulative log percentage of drug remaining vs. time [78], Higuchi as the cumulative percentage of drug permeated vs. square root of time [79], and Korsmeyer-Peppas [80] models were determined, respectively. They were compared to describe the order and mechanism of drug permeation. The value of diffusion exponent " $n$ " was estimated by fitting the permeation data to the KorsmeyerPeppas model, and the mechanism of drug permeation was determined. If the value of $n$ is 0.45 , then the formulation follows the Fickian diffusion. If the value of $n$ is between 0.45 and 0.88 , then the formulation follows an anomalous (non-Fickian) diffusion. If the value of $n$ is 0.89 , then permeation is case II transport, and if the value of $n$ is greater than 0.89 , then the formulation follows super case II transport [81].

\section{Conclusions}

This study demonstrated the successful preparation of CS/CRG-based, NAP nanoparticle-containing gel to be used as a sustained TDDS. NAP-loaded, CS/CRGnanoparticles were successfully synthesized using optimized variables: polymer con- 
centration, drug concentration, and stirring speed proposed by BBD. As a novel approach to nanoparticle-containing gel as a TDDS, this study was initiated to design a polymeric nanoparticle-containing gel using biodegradable polymers through the polyelectrolyte complexation method. Statistical analysis displayed that high polymer concentration (CRG $0.07 \%$ ) and stirring speed (900 rpm) but low drug concentration (30\%) are mandatory for additionally sustained permeation. NAP-loaded CS/CRG nanoparticle-containing Carbopol 940 gel showed sustained permeation of NAP for a period of $48 \mathrm{~h}$ in an ex vivo permeation study using FT rat skin. Ex vivo drug permeation studies verify the sustained liberation of NAP from CS/CRG nanoparticles for $48 \mathrm{~h}$ following a non-Fickian diffusion mechanism and zero-order release kinetics. It has been observed that an optimized batch produced a gel with good consistency, homogeneity, spreadability, stability, and enhanced permeation as compared to the control gel. The acute oral toxicity studies show no signs of incompatibility and toxicity in the developed nanoparticles in histopathological slides. In vivo anti-inflammatory studies confirmed ex vivo study results through an increased inhibition percentage of paw edema and a marked reduction in inflammation markers through histopathological illustrations. The values of the outcome variables were very close to the predicted variables by BBD, which signifies the robustness and reliability of BBD. Accordingly, it is expected that novel NAP-loaded nanoparticle gels can be exploited as a beneficial substitute to treat arthritis via improved permeation profile and better patient compliance.

Author Contributions: Conceptualization and methodology, writing-original draft preparation, S.N.; supervision, F.P.; project administration, A.A.; funding acquisition, M.B.; resources, K.F.; data curation, H.S.; writing-review and editing, I.M.; visualization, G.M. All authors have read and agreed to the published version of the manuscript.

Funding: This research received no external funding.

Institutional Review Board Statement: All procedures performed in studies involving animals were under the ethical standards of the Pharmacy Research Ethics Committee of the Department of Pharmaceutics, Faculty of Pharmacy, The Islamia University of Bahawalpur, after attaining formal approval. The animal trial studies were approved by the Animal Ethics Committee (08-2020/PAEC) as per the Government of Pakistan's accepted laws for animal use in labs.

Informed Consent Statement: Not applicable.

Data Availability Statement: Data is contained within the article.

Conflicts of Interest: The authors declare no conflict of interest.

\section{References}

1. Lubberts, E.; van den Berg, W.B. Cytokines in the Pathogenesis of Rheumatoid Arthritis and Collagen-Induced Arthritis. In Madame Curie Bioscience Database; Landes Bioscience: Austin, TX, USA, 2013.

2. Micheli, L.; Bozdag, M.; Akgul, O.; Carta, F.; Guccione, C.; Bergonzi, M.C.; Bilia, A.R.; Cinci, L.; Lucarini, E.; Parisio, C. Pain Relieving Effect of-NSAIDs-CAIs Hybrid Molecules: Systemic and Intra-Articular Treatments against Rheumatoid Arthritis. Int. J. Mol. Sci. 2019, 20, 1923. [CrossRef] [PubMed]

3. McCarberg, B.; Gibofsky, A. Need to Develop New Nonsteroidal Anti-Inflammatory Drug Formulations. Clin. Ther. 2012, 34, 1954-1963. [CrossRef]

4. Keyhanian, F.; Alizadeh, N.; Shojaie, A. Spectrophotometric determination of Naproxen as ion-pair with bromophenol blue in bulk, pharmaceutical preparation and human serum samples. Curr. Chem. Lett. 2014, 3, 15-22. [CrossRef]

5. Adibkia, K.; Javadzadeh, Y.; Dastmalchi, S.; Mohammadi, G.; Niri, F.K.; Alaei-Beirami, M. Naproxen-eudragit ${ }^{\circledR}$ RS100 nanoparticles: Preparation and physicochemical characterization. Colloids Surf. B Biointerfaces 2011, 83, 155-159. [CrossRef] [PubMed]

6. Guilherme, V.A.; Ribeiro, L.N.M.; Alcântara, A.C.S.; Castro, S.R.; Rodrigues da Silva, G.H.; da Silva, C.G.; Breitkreitz, M.C.; Clemente-Napimoga, J.; Macedo, C.G.; Abdalla, H.B.; et al. Improved efficacy of naproxen-loaded NLC for temporomandibular joint administration. Sci. Rep. 2019, 9, 11160. [CrossRef]

7. Bjarnason, I.; Scarpignato, C.; Holmgren, E.; Olszewski, M.; Rainsford, K.D.; Lanas, A. Mechanisms of damage to the gastrointestinal tract from nonsteroidal anti-inflammatory drugs. Gastroenterology 2018, 154, 500-514. [CrossRef] [PubMed]

8. Wallace, J.L. Prostaglandins, NSAIDs, and gastric mucosal protection: Why doesn't the stomach digest itself? Physiol. Rev. 2008, 88, 1547-1565. [CrossRef]

9. Cheung, K.; Das, D.B. Microneedles for drug delivery: Trends and progress. Drug Deliv. 2016, 23, 2338-2354. [CrossRef] [PubMed] 
10. Müller, M. (Ed.) Sizing, Shaping and Pharmaceutical Applications of Polyelectrolyte Complex Nanoparticles; Springer: Berlin/Heidelberg, Germany, 2012.

11. Qian, F.; Cui, F.; Ding, J.; Tang, C.; Yin, C. Chitosan graft copolymer nanoparticles for oral protein drug delivery: Preparation and characterization. Biomacromolecules 2006, 7, 2722-2727. [CrossRef] [PubMed]

12. Riva, R.; Ragelle, H.; des Rieux, A.; Duhem, N.; Jérôme, C.; Préat, V. Chitosan and Chitosan Derivatives in Drug Delivery and Tissue Engineering. In Chitosan for Biomaterials II; Springer: Berlin/Heidelberg, Germany, 2011; pp. $19-44$.

13. Singla, A.; Chawla, M. Chitosan: Some pharmaceutical and biological aspects-An update. J. Pharm. Pharm. 2001, 53, 1047-1067. [CrossRef] [PubMed]

14. Shu, X.; Zhu, K. Controlled drug release properties of ionically cross-linked chitosan beads: The influence of anion structure. Int. J. Pharm. 2002, 233, 217-225. [CrossRef]

15. Zheng, Z.; Tsai, P.C.; Ramezanli, T.; Michniak-Kohn, B.B. Polymeric nanoparticles-based topical delivery systems for the treatment of dermatological diseases. Wiley Interdiscip. Rev. Nanomed. Nanobiotechnol. 2013, 5, 205-218. [CrossRef]

16. Thein-Han, W.W.; Stevens, W.F. Transdermal delivery controlled by a chitosan membrane. Drug Dev. Ind. Pharm. 2004, 30, 397-404. [CrossRef]

17. Kählig, H.; Hasanovic, A.; Biruss, B.; Höller, S.; Grim, J.; Valenta, C. Chitosan-glycolic acid: A possible matrix for progesterone delivery into skin. Drug Dev. Ind. Pharm. 2009, 35, 997-1002. [CrossRef] [PubMed]

18. Li, X.; Kong, X.; Zhang, Z.; Nan, K.; Li, L.; Wang, X.; Chen, H. Cytotoxicity and biocompatibility evaluation of N, O-carboxymethyl chitosan/oxidized alginate hydrogel for drug delivery application. Int. J. Biol. Macromol. 2012, 50, 1299-1305. [CrossRef] [PubMed]

19. Can, A.; Erdal, M.; Güngör, S.; Özsoy, Y. Optimization and characterization of chitosan films for transdermal delivery of ondansetron. Molecules 2013, 18, 5455-5471. [CrossRef] [PubMed]

20. Bhaskar, K.; Anbu, J.; Ravichandiran, V.; Venkateswarlu, V.; Rao, Y.M. Lipid nanoparticles for transdermal delivery of flurbiprofen: Formulation, in vitro, ex vivo and in vivo studies. Lipids Health Dis. 2009, 8, 6. [CrossRef]

21. Kyriakou, P.; Mouselimis, D.; Tsarouchas, A.; Rigopoulos, A.; Bakogiannis, C.; Noutsias, M.; Vassilikos, V. Diagnosis of cardiac amyloidosis: A systematic review on the role of imaging and biomarkers. BMC Cardiovasc. Disord. 2018, 18, 221. [CrossRef]

22. Kumar, N.; Kumbhat, S. Essentials in Nanoscience and Nanotechnology; Wiley: Hoboken, NJ, USA, 2016.

23. Kalsoom Khan, A.; Saba, A.U.; Nawazish, S.; Akhtar, F.; Rashid, R.; Mir, S.; Nasir, B.; Iqbal, F.; Afzal, S.; Pervaiz, F.; et al. Carrageenan Based Bionanocomposites as Drug Delivery Tool with Special Emphasis on the Influence of Ferromagnetic Nanoparticles. Oxidative Med. Cell. Longev. 2017, 2017, 8158315. [CrossRef]

24. Deka, C.; Dutta, M.; Deka, D.; Jha, D.K.; Kakati, D.K. Study of olive oil-loaded chitosan/carrageenan coacervate and its antibacterial property. Int. J. Pharm. Sci. 2016, 6, 1524-1533.

25. Janes, K.; Calvo, P.; Alonso, M. Polysaccharide colloidal particles as delivery systems for macromolecules. Adv. Drug Deliv. Rev. 2001, 47, 83-97. [CrossRef]

26. Shanmuga, S.; Singhal, M.; Sen, S. Synthesis and Characterization of Carrageenan Coated Magnetic Nanoparticles for Drug Delivery Applications. Transl. Biomed. 2015, 6, 1-3.

27. Mura, P.; Zerrouk, N.; Mennini, N.; Maestrelli, F.; Chemtob, C. Development and characterization of naproxen-chitosan solid systems with improved drug dissolution properties. Eur. J. Pharm. Sci. 2003, 19, 67-75. [CrossRef]

28. Chawla, A.; Sharma, P.; Pawar, P. Eudragit S-100 coated sodium alginate microspheres of naproxen sodium: Formulation, optimization and in vitro evaluation/Alginatne mikrosfere naproksen natrija obložene Eudragitom S-100: Priprava, optimizacija $\mathrm{i}$ in vitro vrednovanje. Acta Pharm. 2012, 62, 529-545. [CrossRef]

29. Sharma, P.; Chawla, A.; Pawar, P. Design, development, and optimization of polymeric based-colonic drug delivery system of naproxen. Sci. World J. 2013, 2013, 654829. [CrossRef] [PubMed]

30. Qi, L.; Xu, Z.; Jiang, X.; Hu, C.; Zou, X. Preparation and antibacterial activity of chitosan nanoparticles. Carbohydr. Res. 2004, 339, 2693-2700. [CrossRef]

31. Tranquilan-Aranilla, C.; Nagasawa, N.; Bayquen, A.; Rosa, A.D. Synthesis and characterization of carboxymethyl derivatives of kappa-carrageenan. Carbohydr. Polym. 2012, 87, 1810-1816. [CrossRef]

32. Li, C.; Hein, S.; Wang, K. Chitosan-carrageenan polyelectrolyte complex for the delivery of protein drugs. ISRN Biomater. 2013, 2013, 629807. [CrossRef]

33. Guo, Z.; Liu, X.-M.; Ma, L.; Li, J.; Zhang, H.; Gao, Y.-P.; Yuan, Y. Effects of particle morphology, pore size and surface coating of mesoporous silica on Naproxen dissolution rate enhancement. Colloids Surf. B Biointerfaces 2013, 101, 228-235. [CrossRef]

34. Lusiana, R.A.; Protoningtyas, W.P.; Wijaya, A.R.; Siswanta, D.; Santosa, S.J. Chitosan-Tripoly Phosphate (CS-TPP) Synthesis Through Cross-linking Process: The Effect of Concentration Towards Membrane Mechanical Characteristic and Urea Permeation. Orient. J. Chem. 2017, 33, 2913-2919. [CrossRef]

35. Mary, I.A.; Selvanayagam, S.; Selvasekarapandian, S.; Chitra, R.; Chandra, M.L.; Ponraj, T. Lithium ion conducting biopolymer membrane based on K-carrageenan with $\mathrm{LiNO}_{3}$. Ionics 2020, 26, 4311-4326. [CrossRef]

36. Shirsat, A.E.; Chitlange, S.S. Application of quality by design approach to optimize process and formulation parameters of rizatriptan loaded chitosan nanoparticles. J. Adv. Pharm. Technol. Res. 2015, 6, 88. [CrossRef]

37. Jana, S.; Manna, S.; Nayak, A.K.; Sen, K.K.; Basu, S.K. Carbopol gel containing chitosan-egg albumin nanoparticles for transdermal aceclofenac delivery. Colloids Surf. B Biointerfaces 2014, 114, 36-44. [CrossRef] 
38. Cooper, D.L.; Harirforoosh, S. Effect of formulation variables on preparation of celecoxib loaded polylactide-co-glycolide nanoparticles. PLoS ONE 2014, 9, e113558. [CrossRef] [PubMed]

39. Bayat, A.; Larijani, B.; Ahmadian, S.; Junginger, H.E.; Rafiee-Tehrani, M. Preparation and characterization of insulin nanoparticles using chitosan and its quaternized derivatives. Nanomed. Nanotechnol. 2008, 4, 115-120. [CrossRef] [PubMed]

40. Bokharaei, M.; Margaritis, A.; Xenocostas, A.; J Freeman, D. Erythropoietin encapsulation in chitosan nanoparticles and kinetics of drug release. Curr. Drug Deliv. 2011, 8, 164-171. [CrossRef] [PubMed]

41. Grenha, A.; Gomes, M.E.; Rodrigues, M.; Santo, V.E.; Mano, J.F.; Neves, N.M.; Reis, R.L. Development of new chitosan/carrageenan nanoparticles for drug delivery applications. J. Biomed. Mater. Res. A 2010, 92, 1265-1272. [CrossRef]

42. Kouchak, M.; Azarpanah, A. Preparation and In Vitro Evaluation of Chitosan Nanoparticles Containing Diclofenac Using the Ion-Gelation Method. Jundishapur J. Nat. Pharm. Prod. 2015, 10, 10. [CrossRef]

43. Shahriari, M.H.; Atai, M.; Zandi, M.; Shokrollahi, P.; Solhi, L. Preparation and characterization of eugenol-loaded oligochitosan nanoparticles through sol-gel and emulsion/sol-gel methods. Polym. Bull. 2018, 75, 3035-3051. [CrossRef]

44. Li, D.; Kaner, R.B. Shape and aggregation control of nanoparticles: Not shaken, not stirred. J. Am. Chem. Soc. 2006, 128, 968-975. [CrossRef]

45. Van de Velde, F.; Knutsen, S.; Usov, A.; Rollema, H.; Cerezo, A. ${ }^{1} \mathrm{H}$ and ${ }^{13} \mathrm{C}$ high resolution NMR spectroscopy of carrageenans: Application in research and industry. Trends Food Sci. Technol. 2002, 13, 73-92. [CrossRef]

46. Bhavin, K.P.; Apurva, R.; Parikh, R.H.; Aboti, P.S. Development of oral sustained release rifampicin loaded chitosan nanoparticles by design of experiment. J. Drug Deliv. 2013, 2013, 370938.

47. Sharma, N.; Madan, P.; Lin, S. Effect of process and formulation variables on the preparation of parenteral paclitaxel-loaded biodegradable polymeric nanoparticles: A co-surfactant study. Asian J. Pharm. Sci. 2016, 11, 404-416. [CrossRef]

48. Basha, B.N.; Prakasam, K.; Goli, D. Formulation and evaluation of gel containing fluconazole-antifungal agent. Int. J. Drug Dev. Res. 2011, 3, 109-128.

49. Kaur, L.P. Topical gel: A recent approach for novel drug delivery. Asian J. Biomed. Pharm. Sci. 2013, 3, 1.

50. Shilakari Asthana, G.; Asthana, A.; Singh, D.; Sharma, P.K. Etodolac Containing Topical Niosomal Gel: Formulation Development and Evaluation. J. Drug Deliv. 2016, 2016, 9324567. [CrossRef]

51. Feng, S.-S. Nanoparticles of biodegradable polymers for new-concept chemotherapy. Expert Rev. Med. Devices 2004, 1, 115-125. [CrossRef]

52. Patel, H.K.; Barot, B.S.; Parejiya, P.B.; Shelat, P.K.; Shukla, A. Topical delivery of clobetasol propionate loaded microemulsion based gel for effective treatment of vitiligo: Ex vivo permeation and skin irritation studies. Colloids Surf. B Biointerfaces 2013, 102, 86-94. [CrossRef] [PubMed]

53. Shivhare, U.; Jain, K.; Mathur, V.; Bhusari, K.; Roy, A. Formulation development and evaluation of diclofenac sodium gel using water soluble polyacrylamide polymer. Dig. J. Nanomater. Biostruct. 2009, 4, 2.

54. Senthil, V.; Kumar, R.S.; Nagaraju, C.; Jawahar, N.; Ganesh, G.; Gowthamarajan, K. Design and development of hydrogel nanoparticles for mercaptopurine. J. Adv. Pharm. Technol. Res. 2010, 1, 334. [CrossRef] [PubMed]

55. Morsi, N.M.; Abdelbary, G.A.; Ahmed, M.A. Silver sulfadiazine based cubosome hydrogels for topical treatment of burns: Development and in vitro/in vivo characterization. Eur. J. Pharm. Biopharm. 2014, 86, 178-189. [CrossRef]

56. Prajapati, S.T.; Patel, C.G.; Patel, C.N. Formulation and evaluation of transdermal patch of repaglinide. ISRN Pharm. 2011, 2011, 651909. [CrossRef]

57. Hafner, A.; Lovrić, J.; Pepić, I.; Filipović-Grčić, J. Lecithin/chitosan nanoparticles for transdermal delivery of melatonin. J. Microencapsul. 2011, 28, 807-815. [CrossRef]

58. Verma, A.; Jain, A.; Hurkat, P.; Jain, S.K. Transfollicular drug delivery: Current perspectives. Res. Rep. Transdermal Drug Deliv. 2016, 5, 1-17.

59. Cong, H.; Khaziakhmetova, V.; Zigashina, L. Rat paw oedema modeling and NSAIDs: Timing of effects. Int. J. Risk Saf. Med. 2015, 27, S76-S77. [CrossRef] [PubMed]

60. Valenta, C.; Schultz, K. Influence of carrageenan on the rheology and skin permeation of microemulsion formulations. J. Control. Release 2004, 95, 257-265. [CrossRef]

61. Rodrigues, S.; da Costa, A.M.R.; Grenha, A. Chitosan/carrageenan nanoparticles: Effect of cross-linking with tripolyphosphate and charge ratios. Carbohydr. Polym. 2012, 89, 282-289. [CrossRef] [PubMed]

62. Amini, Y.; Amel Jamehdar, S.; Sadri, K.; Zare, S.; Musavi, D.; Tafaghodi, M. Different methods to determine the encapsulation efficiency of protein in PLGA nanoparticles. Biomed. Mater. Eng. 2017, 28, 613-620. [CrossRef]

63. Rescignano, N.; Tarpani, L.; Tiribuzi, R.; Montesano, S.; Martino, S.; Latterini, L.; Kenny, J.M.; Armentano, I. Protein encapsulation in biodegradable polymeric nanoparticles: Morphology, fluorescence behaviour and stem cell uptake. Macromolecules 2013, 13, 1204-1212. [CrossRef] [PubMed]

64. Ankanna, S.; Tollamadugu Prasad, N.V.K.V.; Elumalai, E.; Savithramma, N. Production of biogenic silver nanoparticles using Boswellia ovalifoliolata stem bark. Dig. J. Nanomater. Biostruct. 2010, 5, 369-372.

65. Surassmo, S.; Saengkrit, N.; Ruktanonchai, U.R.; Suktham, K.; Woramongkolchai, N.; Wutikhun, T.; Puttipipatkhachorn, S. Surface modification of PLGA nanoparticles by carbopol to enhance mucoadhesion and cell internalization. Colloids Surf. B Biointerfaces 2015, 130, 229-236. [CrossRef] [PubMed] 
66. Garg, A.; Sachdeva, R.; Kapoor, G. Comparison of crystalline and amorphous carriers to improve the dissolution profile of water insoluble drug itraconazole. Int. J. Pharm. Biol. Sci. 2013, 4, 934-948.

67. Sadaquat, H.; Akhtar, M.; Nazir, M.; Ahmad, R.; Alvi, Z.; Akhtar, N. Biodegradable and biocompatible polymeric nanoparticles for enhanced solubility and safe oral delivery of docetaxel: In vivo toxicity evaluation. Int. J. Pharm. 2021, 598, 120363. [CrossRef]

68. Helal, D.A.; El-Rhman, D.A.; Abdel-Halim, S.A.; El-Nabarawi, M.A. Formulation and evaluation of fluconazole topical gel. Int. J. Pharm. Pharm. Sci. 2012, 4, 176-183.

69. Sareen, R.; Kumar, S.; Gupta, G.D. Meloxicam carbopol-based gels: Characterization and evaluation. Curr. Drug Deliv. 2011, 8, 407-415. [CrossRef]

70. Gupta, A.; Mishra, A.; Singh, A.; Gupta, V.; Bansal, P. Formulation and evaluation of topical gel of diclofenac sodium using different polymers. Drug Invent. Today 2010, 2, 250-253.

71. Sera, U.; Ramana, M. In vitro skin absorption and drug release-a comparison of four commercial hydrophilic gel preparations for topical use. Indian Pharm. 2006, 73, 356-360.

72. Bachhav, Y.; Patravale, V. Formulation of meloxicam gel for topical application: In vitro and in vivo evaluation. Acta Pharm. 2010, 60, 153-163. [CrossRef]

73. Bachhav, Y.G.; Patravale, V.B. Microemulsion-based vaginal gel of clotrimazole: Formulation, in vitro evaluation, and stability studies. AAPS PharmSciTech. 2009, 10, 476. [CrossRef]

74. Aletaha, D.; Neogi, T.; Silman, A.J.; Funovits, J.; Felson, D.T.; Bingham, C.O.; Birnbaum, N.S.; Burmester, G.R.; Bykerk, V.P.; Cohen, M.D. 2010 rheumatoid arthritis classification criteria: An American College of Rheumatology/European League against Rheumatism collaborative initiative. Arthritis Rheumatol. 2010, 62, 2569-2581. [CrossRef]

75. Fang, J.-Y.; Yu, S.-Y.; Wu, P.-C.; Huang, Y.-B.; Tsai, Y.-H. In vitro skin permeation of estradiol from various proniosome formulations. Int. J. Pharm. 2001, 215, 91-99. [CrossRef]

76. Renju, G.; Muraleedhara Kurup, G.; Saritha Kumari, C. Anti-inflammatory activity of lycopene isolated from Chlorella marina on Type II Collagen induced arthritis in Sprague Dawley rats. Immunopharmacol. Immunotoxicol. 2013, 35, 282-291. [CrossRef] [PubMed]

77. Freitas, M.; Marchetti, J. Nimesulide PLA microspheres as a potential sustained release system for the treatment of inflammatory diseases. Int. J. Pharm. 2005, 295, 201-211. [CrossRef] [PubMed]

78. Sun, L.; Chen, Y.; Zhou, Y.; Guo, D.; Fan, Y.; Guo, F.; Zheng, Y.; Chen, W. Preparation of 5-fluorouracil-loaded chitosan nanoparticles and study the sustained release in vitro and in vivo. Asian J. Pharm. Sci. 2017, 12, 418-423. [CrossRef]

79. Derakhshandeh, K.; Soheili, M.; Dadashzadeh, S.; Saghiri, R. Preparation and in vitro characterization of 9-nitrocamptothecinloaded long circulating nanoparticles for delivery in cancer patients. Int. J. Nanomed. 2010, 5, 463. [CrossRef] [PubMed]

80. Dash, S.; Murthy, P.N.; Nath, L.; Chowdhury, P. Kinetic modeling on drug release from controlled drug delivery systems. Acta Pol. Pharm. 2010, 67, 217-223. [PubMed]

81. Muhamad, I.I.; Selvakumaran, S.; Lazim, N.A.M. Designing polymeric nanoparticles for targeted drug delivery system. Nanomedicine 2014, 287, 287. 